\title{
PARTICIPACION LABORAL DE LA MUJER, NATALIDAD Y TAMAÑO DE COHORTES
}

Enrique Gil Calvo

Universidad Complutense de Madrid

RESUMEN. Tras introducir la metodología de la estratificación por cohortes, el artículo analiza longitudinalmente los recientes cambios experimentados por la participación laboral de las mujeres españolas, examinando su asociación con el tamaño de las cohortes. Ta. les resultados se relacionan posteriormente con la evolución de la natalidad y la proporción relativa de jóvenes, en comparación con la evidencia europea más reciente.

La caída reciente de la fecundidad corre paralela a la profunda metamorfosis que atraviesan los papeles asociados a la posición femenina en la actualidad. Aparece así un conflicto abierto entre la reproducción demográfica y la masiva incorporación de la mujer al mercado de trabajo. Tal dilema, de hacerse irreversible, amenaza agudizar las graves contradicciones de la estructura poblacional. Para clarificar su posible resolución futura se proponen análisis basados en la metodología longitudinal de la estratificación por cohortes generacionales que recientemente ha desarrollado la sociología de la edad. $\mathrm{Al}$ efecto, y tras unas iniciales consideraciones teóricas, se aplica el modelo al estudio de los cambios recientes experimentados por el empleo femenino

* Este trabajo se benefició de sendas investigaciones dirigidas por el autor y llevadas a cabo, durante 1986 y 1987, por María Piniella del Valle y Elena Menéndez Vergara, sociólogas, por encargo, respectivamente, del Centro de Investigaciones Sociológicas y el Instituto de la Mujer. 
en España y al análisis de las oscilaciones en la proporción relativa de jóvenes comparativamente registradas en diversos países de Europa.

\section{Sociología de la edad y estratificación por cobortes}

Si bien la edad es el efecto del paso del tiempo sobre la vida de las personas, el análisis sociológico puede extender por analogía el concepto para que abarque los efectos del paso del tiempo sobre unidades de observación de nivel supraindividual: grupos, organizaciones, colectividades. Por ello, la sociología de la edad no está sólo interesada en los procesos de envejecimiento personal: debe atender, además, al modo en que las personas envejecen colectivamente vinculadas. Por consiguiente, la edad de las colectividades debe formar parte también de su objeto de estudio. $\mathrm{Y}$ el ejemplo más obvio es el de las cohortes generacionales, o colectivos de coetáneos.

Tras los pioneros avances realizados por Norman Ryder durante la década de los sesenta ${ }^{1}$, la sociología de la edad se ha venido desarrollando últimamente mediante su enfoque privilegiado en el análisis de la estratificación por cohortes ${ }^{2}$. Ello no ha significado un abandono de la perspectiva individualista, específicamente representada por la escuela de psicología social denominada de desarrollo bumano o perspectiva life-span (curso vital) ${ }^{3}$. Antes bien, lo que plantea la sociología de la edad es un paradigma multidimensional cuyo mapa cognitivo sea capaz de modelizar tanto las perspectivas individuales como las colectivas. A este respecto, he aquí lo que bien pudiera ser un tentativo esquema sintético ${ }^{4}$.

El efecto del paso del tiempo sobre los cursos de vida (individuales o colectivos) puede ser analizado de acuerdo a dos dimensiones distintas: la perspectiva transversal (comparación sincrónica de distintas unidades vitales, observadas en el mismo instante del curso del tiempo) y la perspectiva longitudinal (comparación diacrónica de distintas observaciones sucesivas, realizadas sobre la misma unidad vital, a lo largo de sucesivos momentos de observación, separados entre sí por determinados lapsos periódicos de tiempo).

La articulación de estas dos dimensiones metodológicas puede ser gráficamente representada por el esquema de la figura $1^{5}$. Y surge así, visualmente intuida, la doble perspectiva de la estratificación por edad. En efecto, la

1 Véanse Ryder (1965) y Ryder (1968).

${ }^{2}$ Los principales readings son: Riley, Johnson y Foner (1972); Riley (1979); Riley, Abeles y Teitelbaum (1981), y Binstock y Shanas (1985).

${ }^{3}$ Puede consultarse el libro de Kertzer y Keith (1984), así como el artículo de Featherman y Lerner (1985). Entre nosotros acaba de aparecer una obra colectiva, precisamente centrada en el desarrollo del género, que utiliza la metodología life-span: véase Fernández (1988).

4 Extraído de una muy reciente síntesis elaborada por la más reconocida especialista en el tema: Mathilda W/hite Riley. Véase Riley, Foner y Waring (1988).

${ }_{5}^{5}$ Véase Riley, Foner y Waring (1988), en la p. 245 del manual de Smelser (1988). 


\section{FIGURA 1}

\section{Estratificación por cobortes $v$ estratificación por edades}

Tiempo Individual

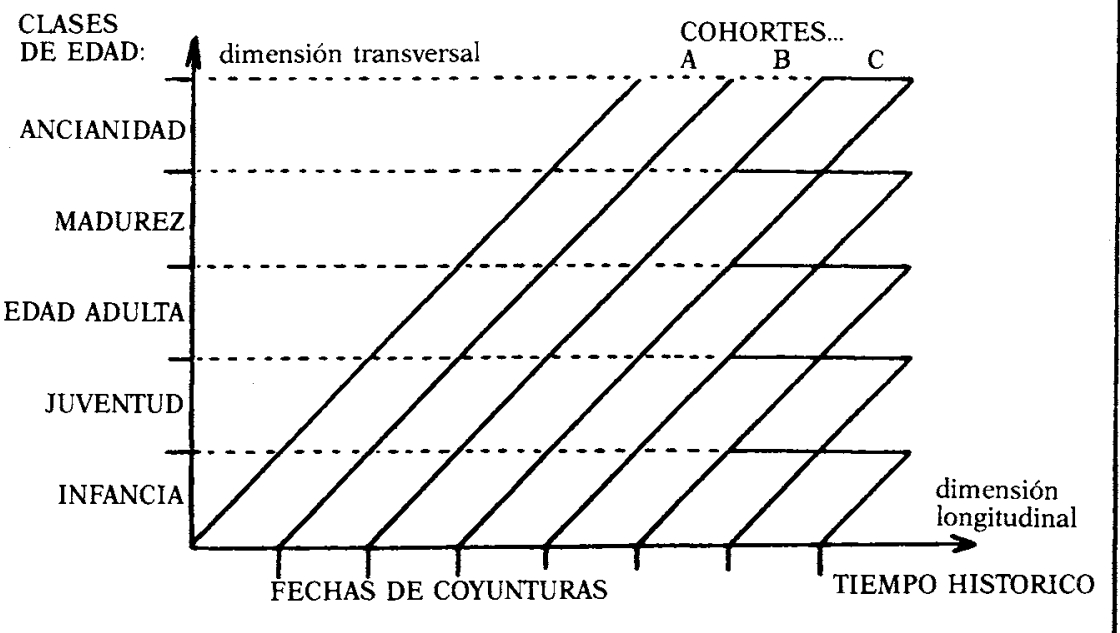

Fuente: El esquema de la estratificación por edad, adaptado de M. W. Riley et al. (1988), p. 245.

conducta de los individuos varía sobremanera en función de su edad: y los segmentos de comportamiento así diferenciados representan la estratificación por edad. Ahora bien, coexisten dos sistemas de estratificación por edad. El compuesto por el sistema de las clases de edad, que determinan asignaciones específicas de posiciones sociales (y de roles asociados a ellas), diferencialmente ocupables en función de la edad, y el resultante de la coexistencia, en un momento dado, de sucesivas cohortes generacionales, cada una de las cuales se halla atravesando diferentes pero consecutivas etapas de su ciclo vital colectivo.

Por una parte, puesto que las posiciones ocupadas determinan la conducta en función de los roles que prescriben, y tales posiciones son diferencialmente asignadas en función de la edad, los individuos, a lo largo de su curso de vida, se van viendo obligados, con voluntad o sin ella, a ir cambiando de conducta conforme cambian de edad. $\mathrm{Y}$, así, estos cambios necesarios de conducta determinan que ésta resulte estratificada en función de la edad. Tal estratificación, que podemos calificar de horizontal con arreglo al eje de coordenadas que el gráfico de la figura 1 representa, determina la división 
de cada sistema social en ciertas clases de edad: infancia, juventud, edad adulta, madurez, ancianidad, etc.; a lo largo de un ciclo vital cuya trayectoria exhibe un sentido de dirección tan irreversible como necesaria.

Pero, por otra parte, no es lo mismo cambiar de edad, y de consecuente etapa vital, bajo una determinada coyuntura colectiva que bajo otra distinta, opuesta quizá. ¿Qué hay de común entre ser joven durante los sesenta y ser joven durante los ochenta? Existen cambios que no se deben a la edad de los individuos (que cambian con el paso del tiempo), sino al cambio de los colectivos (que se suceden unos a otros con el paso del tiempo).

En consecuencia, por el otro lado del esquema, tales cambios de conducta asociados a la edad aparecen igualmente determinados por las propiedades características, endógenas y exógenas, de la cohorte generacional a la que se pertenezca ${ }^{6}$. En efecto, el proceso de paulatino envejecimiento se desarrolla en un mismo y común marco histórico de referencia, determinado tanto política como económicamente, que es sincrónicamente compartido con todos los coetáneos, con quienes se establecen y anudan lazos y vínculos tanto de solidaridad e intimidad como de pertenencia y referencia o de conflicto, competencia y rivalidad.

Así, todo el colectivo de coetáneos comparte el mismo común denominador, que a todos sus miembros determina al establecer un mismo marco generacional bajo el que vivir los cambios de edad y al que tener que adaptarse. Y ese común denominador, específico para cada cohorte, y que a todos sus miembros afecta, no es sólo de naturaleza exógena (la cambiante coyuntura histórico-política y socioeconómica a la que deben adaptarse conforme cam. bian de edad), sino de naturaleza endógena, además.

En efecto, cada cohorte, desde que nace y conforme va realizando sucesivas elecciones irreversibles, va adquiriendo una serie de propiedades características que le van siendo inherentes y que, acumulándose, van conformando la determinación del destino que en el futuro le aguarda. Semejante naturaleza intrínseca es privativa de cada cohorte, singular y específica, y no puede ser compartida con ninguna otra.

Los elementos definitorios de las propiedades endógenas de cada cohorte son múltiples y variados. Ante todo, claro está, y desde el mismo lapso de tiempo en que se produce su nacimiento, el tamaño relativo que posee respecto al resto de cohortes contiguas adyacentes. Este tamaño relativo es inversamente proporcional al nivel de oportunidades vitales que le aguardan objetivamente. En efecto, a igualdad del resto de factores, o bajo condiciones exógenas (coyuntura histórica) constantes, las cohortes de más reducidos efectivos disponen de mayores y mejores oportunidades vitales que las más numerosas ( $\mathrm{y}$ viceversa). Tales oportunidades se refieren, por supuesto, a opor-

- Una teoría de los ciclos políticos, basada en la teoría de las generaciones de Ortega, aparece en Schlesinger (1986). Pero mucho más interesantes son los análisis de su fuente inspiradora: Hirschman (1982). 
tunidades de enseñanza, de empleo, de nivel salarial, de matrimonio, de descendencia, etc.

$Y$, después del tamaño relativo, las siguientes propiedades endógenas características, en orden de importancia, se refieren a las cualificaciones que van adquiriendo los miembros de la cohorte, y que, al agregarse colectivamente, confieren al conjunto sus propiedades emergentes: escolaridad, actividad económica, nupcialidad, etc. En este sentido, son particularmente importantes los efectos del calendario: umbrales cronológicos (turning points) que marcan los comienzos y terminaciones de los sucesos más característicos. ¿A qué edad abandona cada cohorte, en promedio, la enseñanza formal; a qué edad comienza mayoritariamente a trabajar; a qué edad inicia su calendario matrimonial y reproductor, etc.? La respuesta a tales preguntas, y a otras análogas a éstas, constituye la clave capaz de explicar el destino futuro de la cohorte. Pues la determinación por el pasado, y no por el presente, es lo que distingue y diferencia a la metodología longitudinal (que explica los hechos actuales y las proyecciones de futuro como consecuencias de los orígenes antecedentes) de la transversal (que explica los hechos del presente mediante su comparación con otros hechos igualmente actuales pero independientes aunque yuxtapuestos: sin ser capaz, en consecuencia, de proyectar tendencias hacia el futuro con legitimidad explicativa).

Cabe concluir, en fin, que la doble estratificación por edades se debe tanto a la segmentación social por clases de edad (que divide a la sociedad en categorías desiguales, cada una dotada de diferentes estatutos de derechos/ deberes y de distintos balances de expectativas/oportunidades) como a la segmentación social por cohortes generacionales. Por esta última, la sociedad queda dividida en unos invisibles compartimentos estancos (los colectivos de coetáneos a los que se pertenece) de un modo tan determinista e inamovible que se diría dictado por el destino estamental de la cuna y la casta (nunca mejor dicho, siendo la pertenencia a una cohorte mera cuestión de nacimiento). Pues, en efecto, si bien la segmentación por clases de edad está claramente compensada por esa movilidad social perfectamente democrática que es el igualitario envejecimiento inevitable, la segmentación por cohortes, por el contrario, no aparece compensada por ningún mecanismo igualador o nivelador, capaz de servir de puente intergeneracional. En efecto, no hay posible movilidad social entre unas cohortes sociales y otras, pues la pertenencia a la generación de nacimiento (a diferencia de la edad, que es un status adquirido) es un estigma irreversible que, como status adscrito, acompaña desde la cuna a la tumba. Así, en nuestra sociedad meritocrática, que tiende idealmente hacia la transparente movilidad perfecta, la segmentación por cohortes implica una suerte de regresión estamental hacia una cierta impermeabilidad social. 


\section{Análisis longitudinal y empleo femenino}

El análisis de cohortes exige una metodología longitudinal cuya utilización resulta muchas veces imposible por ausencia de series históricas de datos homogéneos. En consecuencia, la mayor parte de las veces es preciso recurrir en exclusiva a perfiles transversales, bastante más accesibles. El problema, sin embargo, es que, a la hora de interpretar los datos y extraer conclusiones, muchas veces utilizamos fuentes transversales pero las leemos como si fuesen longitudinales.

\section{TABLA 1}

Evolución transversal del empleo en España.

Variaciones porcentuales en volumen, tasas y cuotas de empleo.

\begin{tabular}{|c|c|c|c|c|c|c|c|c|c|}
\hline \multirow[b]{2}{*}{ Grupos edad } & \multicolumn{3}{|c|}{$\begin{array}{l}\% \text { variación } 1979-1984 \\
(1979=100)\end{array}$} & \multicolumn{3}{|c|}{$\begin{array}{c}\text { \% variación } 1981-1986 \\
(1981=100)\end{array}$} & \multicolumn{3}{|c|}{$\begin{array}{c}\% \text { variación } 1983-1988 \\
(1983=100)\end{array}$} \\
\hline & $V$ & $T$ & $Q$ & $V$ & $T$ & $Q$ & $V$ & $T$ & $Q$ \\
\hline \multicolumn{10}{|l|}{ Varones: } \\
\hline $\begin{array}{l}16-19 \text { años } . . \\
20-24 \text { años } . \\
25-29 \text { años .. }\end{array}$ & $\begin{array}{r}47 \\
87 \\
102\end{array}$ & $\begin{array}{l}59 \\
76 \\
84\end{array}$ & $\begin{array}{r}53 \\
98 \\
114\end{array}$ & $\begin{array}{r}75 \\
103 \\
118\end{array}$ & $\begin{array}{l}74 \\
92 \\
93\end{array}$ & $\begin{array}{r}74 \\
102 \\
116\end{array}$ & $\begin{array}{l}105 \\
140 \\
122\end{array}$ & $\begin{array}{r}99 \\
126 \\
100\end{array}$ & $\begin{array}{r}95 \\
125 \\
109\end{array}$ \\
\hline $\begin{array}{l}30.34 \text { años } . . \\
35.39 \text { años } . . \\
40.44 \text { años .. }\end{array}$ & $\begin{array}{l}93 \\
99 \\
92\end{array}$ & $\begin{array}{l}90 \\
92 \\
92\end{array}$ & $\begin{array}{l}105 \\
111 \\
103\end{array}$ & $\begin{array}{l}106 \\
107 \\
113\end{array}$ & $\begin{array}{l}95 \\
97 \\
97\end{array}$ & $\begin{array}{l}105 \\
106 \\
112\end{array}$ & $\begin{array}{l}117 \\
105 \\
121\end{array}$ & $\begin{array}{l}102 \\
102 \\
102\end{array}$ & $\begin{array}{r}105 \\
94 \\
109\end{array}$ \\
\hline $\begin{array}{l}45-49 \text { años } . . \\
50-54 \text { años } . . \\
55-59 \text { años } . .\end{array}$ & $\begin{array}{l}76 \\
95 \\
89\end{array}$ & $\begin{array}{l}90 \\
92 \\
85\end{array}$ & $\begin{array}{r}85 \\
107 \\
99\end{array}$ & $\begin{array}{l}81 \\
94 \\
96\end{array}$ & $\begin{array}{l}96 \\
95 \\
88\end{array}$ & $\begin{array}{l}80 \\
93 \\
95\end{array}$ & $\begin{array}{l}95 \\
93 \\
97\end{array}$ & $\begin{array}{r}104 \\
100 \\
92\end{array}$ & $\begin{array}{l}86 \\
84 \\
87\end{array}$ \\
\hline \multicolumn{10}{|l|}{ Mujeres: } \\
\hline $\begin{array}{l}16-19 \text { años } . . \\
20-24 \text { años .. } \\
25-29 \text { años .. }\end{array}$ & $\begin{array}{r}42 \\
77 \\
121\end{array}$ & $\begin{array}{r}53 \\
67 \\
103\end{array}$ & $\begin{array}{r}47 \\
86 \\
136\end{array}$ & $\begin{array}{r}71 \\
88 \\
141\end{array}$ & $\begin{array}{r}68 \\
77 \\
112\end{array}$ & $\begin{array}{r}70 \\
87 \\
139\end{array}$ & $\begin{array}{l}109 \\
114 \\
128\end{array}$ & $\begin{array}{l}107 \\
103 \\
109\end{array}$ & $\begin{array}{r}98 \\
102 \\
115\end{array}$ \\
\hline $\begin{array}{l}30-34 \text { años } . . \\
35-39 \text { años .. } \\
40-44 \text { años .. }\end{array}$ & $\begin{array}{r}115 \\
103 \\
95\end{array}$ & $\begin{array}{r}119 \\
99 \\
98\end{array}$ & $\begin{array}{l}129 \\
116 \\
107\end{array}$ & $\begin{array}{l}142 \\
121 \\
115\end{array}$ & $\begin{array}{r}130 \\
111 \\
99\end{array}$ & $\begin{array}{l}140 \\
119 \\
113\end{array}$ & $\begin{array}{l}139 \\
125 \\
138\end{array}$ & $\begin{array}{l}123 \\
125 \\
113\end{array}$ & $\begin{array}{l}124 \\
112 \\
124\end{array}$ \\
\hline $\begin{array}{l}45-49 \text { años } . \\
50-54 \text { años } . \\
55-59 \text { años .. }\end{array}$ & $\begin{array}{l}78 \\
95 \\
95\end{array}$ & $\begin{array}{l}92 \\
91 \\
89\end{array}$ & $\begin{array}{r}88 \\
106 \\
107\end{array}$ & $\begin{array}{r}80 \\
102 \\
98\end{array}$ & $\begin{array}{l}97 \\
97 \\
95\end{array}$ & $\begin{array}{r}79 \\
100 \\
97\end{array}$ & $\begin{array}{r}98 \\
95 \\
109\end{array}$ & $\begin{array}{l}106 \\
101 \\
102\end{array}$ & $\begin{array}{l}89 \\
85 \\
97\end{array}$ \\
\hline
\end{tabular}

$V:$ Volumen de empleo. Número de personas ocupadas, en miles.

$T$ : Tasa de empleo. Porcentaje de personas ocupadas sobre el total poblacional de cada grupo de sexo y edad.

$Q$ : Cuota de empleo. Porcentaje de personas ocupadas de cada grupo de sexo y edad sobre la población ocupada total.

Fuente: Encuesta de Población Activa, cuarto trimestre de cada año. 
En la tabla 1 se recogen datos acerca de las principales magnitudes que permiten medir la evolución reciente del mercado español de trabajo. La base analizada es la distribución por edad y sexo de la población ocupada, tal como la registra la Encuesta de Población Activa. El período, con ser de sólo diez años (1979-1988), abarca tanto la fase más grave de la reciente crisis de empleo (1979-1984) como el inicio de la incipiente recuperación (1985-1988). En consecuencia, las variaciones experimentadas por las distintas magnitudes seleccionadas (población ocupada, tasa absoluta de ocupación y cuota de ocupación sobre el total de ocupados) debieran ser no sólo intensas, sino especialmente significativas. Y de hecho, efectivamente, así lo son. Pero ¿cómo interpretarlas?

La mayor parte de las veces suele hacerse una lectura transversal de tales datos; y yo mismo caí de lleno en semejante falacia ${ }^{7}$. La consecuencia es exagerar la discriminación por edades del mercado de trabajo: los jóvenes y los más mayores pierden posiciones a pasos agigantados; y los adultos, en perjuicio de los demás, consolidan sobremanera las suyas. Sin embargo, tal interpretación puede ser falaz y sesgada, como consecuencia de un efecto óptico inducido por la perspectiva transversal utilizada. Para reducir ese ruido y eliminar esa distorsión se hace preciso utilizar metodologías longitudinales: algo que pocas veces se ha hecho, según mis noticias, si exceptuamos autores aislados como Zárraga o Garrido ${ }^{8}$.

La tabla 2 recoge los mismos datos que la tabla 1, pero esta vez organizados longitudinalmente: no por edad, como en los perfiles transversales de la tabla 1, sino por años de nacimiento, lo que permite reconstruir las variaciones experimentadas por cada cohorte. Se advertirá que los resultados no podrían ser más dispares. Indican, en efecto, variaciones no menos violentas y significativas. Pero su sentido resulta por completo opuesto al anterior.

Para captar las diferencias, nada más conveniente que seleccionar un conjunto de variaciones concretas (las experimentadas de 1979 a 1984, lapso durante el que el desempleo crecía de forma imparable) y comparar entre sí las dos versiones contrapuestas, transversal y longitudinal: es lo que se refleja gráficamente en la figura 2. En la mitad superior aparecen los dos perfiles transversales, masculino y femenino. Tres rasgos se aprecian inmediatamente. Primero, a pesar de la disminución global del empleo, los adultos experimentan fuertes ganancias a costa de los jóvenes. Segundo, el perfil por edades resulta análogo en ambos géneros. $\mathrm{Y}$ tercero, si bien en términos relativos las mujeres se comportan como los varones, en términos absolutos experimentan ganancias claramente mayores.

7 Véanse Gil Calvo (1986a) y Gil Calvo (1986 b).

${ }^{8}$ Véanse pp. 371 a 374 del libro de Zárraga (1985), y pp. 319 a 404 de la tesis doctoral inédita de Garrido Medina (1988). 


\section{TABLA 2}

Evolución longitudinal del empleo en España. Variaciones porcentuales en volumen, tasas y cuotas de empleo.

\begin{tabular}{|c|c|c|c|c|c|c|}
\hline \multirow[b]{2}{*}{ Cobortes } & \multicolumn{3}{|c|}{ Varones } & \multicolumn{3}{|c|}{ Mujeres } \\
\hline & $V$ & $T$ & $Q$ & $V$ & $T$ & $Q$ \\
\hline \multicolumn{7}{|l|}{$\begin{array}{l}\text { \% variación } 1979-1984 \\
(1979=100)\end{array}$} \\
\hline \multicolumn{7}{|l|}{ Nacidos entre: } \\
\hline $\begin{array}{lllllll}1960 & \text { y } & 1964 & \ldots & \ldots & \ldots & \ldots \\
1955 \text { y } & 1959 & \ldots & \ldots & \ldots & \ldots \\
1950 & \text { y } & 1954 & \ldots & \ldots & \ldots & \ldots\end{array}$ & $\begin{array}{l}106 \\
119 \\
104\end{array}$ & $\begin{array}{r}113 \\
138 \\
97\end{array}$ & $\begin{array}{l}120 \\
133 \\
116\end{array}$ & $\begin{array}{r}103 \\
81 \\
93\end{array}$ & $\begin{array}{r}115 \\
85 \\
90\end{array}$ & $\begin{array}{r}115 \\
91 \\
104\end{array}$ \\
\hline 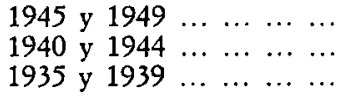 & $\begin{array}{l}99 \\
93 \\
84\end{array}$ & $\begin{array}{l}94 \\
92 \\
88\end{array}$ & $\begin{array}{r}111 \\
105 \\
94\end{array}$ & $\begin{array}{r}101 \\
95 \\
90\end{array}$ & $\begin{array}{r}100 \\
96 \\
92\end{array}$ & $\begin{array}{l}113 \\
106 \\
102\end{array}$ \\
\hline $\begin{array}{llllll}1930 \text { y } 1934 & \ldots & \ldots & \ldots & \ldots \\
1925 \text { y } 1929 & \ldots & \ldots & \ldots & \ldots \\
1920 \text { y } 1924 & \ldots & \ldots & \ldots & \ldots\end{array}$ & $\begin{array}{l}88 \\
77 \\
56\end{array}$ & $\begin{array}{l}88 \\
79 \\
61\end{array}$ & $\begin{array}{l}99 \\
87 \\
63\end{array}$ & $\begin{array}{l}86 \\
81 \\
63\end{array}$ & $\begin{array}{l}84 \\
83 \\
66\end{array}$ & $\begin{array}{l}97 \\
91 \\
71\end{array}$ \\
\hline \multicolumn{7}{|l|}{$\begin{array}{l}\% \text { variación } 1981-1986 \\
(1981=100)\end{array}$} \\
\hline \multicolumn{7}{|l|}{ Nacidos entre: } \\
\hline $\begin{array}{lllllll}1962 & \text { y } & 1966 & \ldots & \ldots & \ldots & \ldots \\
1957 \text { y } & 1961 & \ldots & \ldots & \ldots & \ldots \\
1952 & \text { y } & 1956 & \ldots & \ldots & \ldots & \ldots\end{array}$ & $\begin{array}{l}183 \\
135 \\
116\end{array}$ & $\begin{array}{l}147 \\
159 \\
107\end{array}$ & $\begin{array}{l}181 \\
133 \\
115\end{array}$ & $\begin{array}{r}176 \\
97 \\
119\end{array}$ & $\begin{array}{l}148 \\
105 \\
104\end{array}$ & $\begin{array}{r}173 \\
96 \\
117\end{array}$ \\
\hline $\begin{array}{lllllll}1947 & \text { y } & 1951 & \ldots & \ldots & \ldots & \ldots \\
1942 & \text { y } & 1946 & \ldots & \ldots & \ldots & \ldots \\
1937 & \text { y } & 1941 & \ldots & \ldots & \ldots & \ldots\end{array}$ & $\begin{array}{r}111 \\
104 \\
99\end{array}$ & $\begin{array}{r}100 \\
97 \\
95\end{array}$ & $\begin{array}{r}110 \\
103 \\
98\end{array}$ & $\begin{array}{r}115 \\
106 \\
99\end{array}$ & $\begin{array}{r}106 \\
97 \\
96\end{array}$ & $\begin{array}{r}114 \\
105 \\
98\end{array}$ \\
\hline $\begin{array}{lllllll}1932 & \text { y } 1936 & \ldots & \ldots & \ldots & \ldots \\
1927 & \text { y } & 1931 & \ldots & \ldots & \ldots & \ldots \\
1922 & \text { y } & 1926 & \ldots & \ldots & \ldots & \ldots\end{array}$ & $\begin{array}{l}92 \\
79 \\
55\end{array}$ & $\begin{array}{l}92 \\
81 \\
59\end{array}$ & $\begin{array}{l}91 \\
78 \\
55\end{array}$ & $\begin{array}{l}95 \\
79 \\
65\end{array}$ & $\begin{array}{l}91 \\
81 \\
67\end{array}$ & $\begin{array}{l}94 \\
77 \\
64\end{array}$ \\
\hline \multicolumn{7}{|l|}{$\begin{array}{l}\% \text { variación } 1983-1988 \\
(1983=100)\end{array}$} \\
\hline \multicolumn{7}{|l|}{ Nacidos entre: } \\
\hline 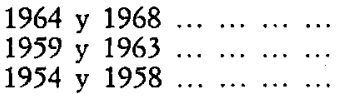 & $\begin{array}{l}296 \\
160 \\
117\end{array}$ & $\begin{array}{l}230 \\
182 \\
114\end{array}$ & $\begin{array}{l}266 \\
143 \\
105\end{array}$ & $\begin{array}{l}254 \\
114 \\
113\end{array}$ & $\begin{array}{l}212 \\
121 \\
107\end{array}$ & $\begin{array}{l}228 \\
102 \\
101\end{array}$ \\
\hline 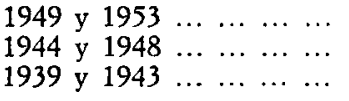 & $\begin{array}{l}115 \\
105 \\
105\end{array}$ & $\begin{array}{l}106 \\
102 \\
101\end{array}$ & $\begin{array}{r}103 \\
94 \\
94\end{array}$ & $\begin{array}{l}112 \\
120 \\
111\end{array}$ & $\begin{array}{l}105 \\
114 \\
103\end{array}$ & $\begin{array}{r}100 \\
108 \\
99\end{array}$ \\
\hline $\begin{array}{lllllll}1934 & \text { y } & 1938 & \ldots & \ldots & \ldots & \ldots \\
1929 & \text { y } & 1933 & \ldots & \ldots & \ldots & \ldots \\
1924 & \text { y } & 1928 & \ldots & \ldots & \ldots & \ldots\end{array}$ & $\begin{array}{l}98 \\
83 \\
59\end{array}$ & $\begin{array}{l}97 \\
83 \\
61\end{array}$ & $\begin{array}{l}88 \\
75 \\
53\end{array}$ & $\begin{array}{l}95 \\
89 \\
72\end{array}$ & $\begin{array}{l}90 \\
88 \\
72\end{array}$ & $\begin{array}{l}85 \\
80 \\
64\end{array}$ \\
\hline
\end{tabular}

$V$ : Volumen de empleo. Número de ocupados, en miles.

$T$ : Tasa de empleo. Porcentaje de ocupados sobre población total de cada grupo de edad y sexo.

Q: Cuota de empleo. Porcentaje de ocupados de cada grupo de edad y sexo sobre el total de ocupados.

Fuente: Encuesta de Población Activa, cuarto trimestre de cada año. 


\section{FIGURA 2}

\section{Evolución transversal y longitudinal del empleo}

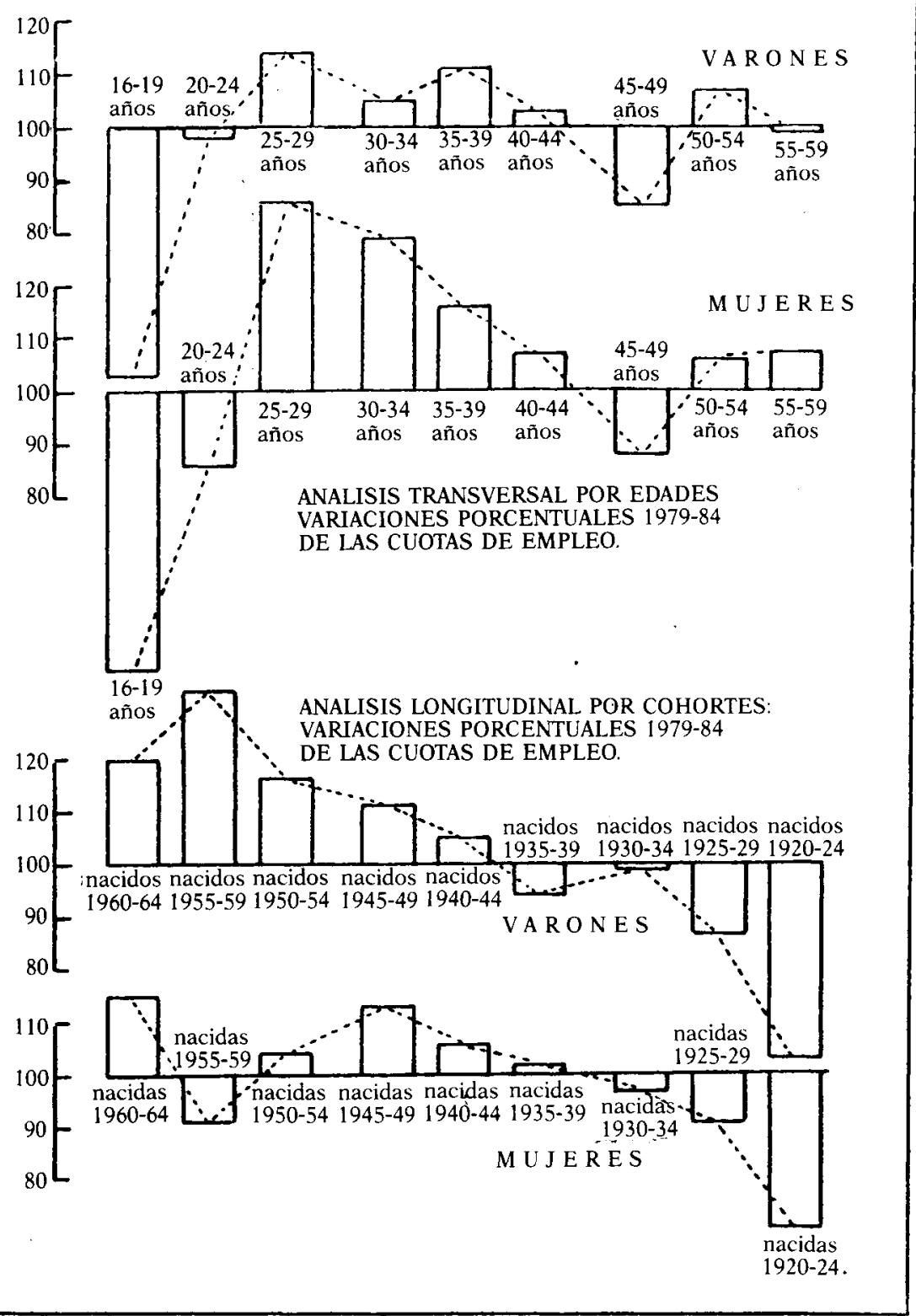

FUENTE: Tablas 1 y 2. 
En cambio, fijemos ahora nuestra atención en la mitad inferior de la figura 2, donde aparecen los perfiles longitudinales de las mismas variaciones. Pues bien, aquí resultan claramente invertidos los tres rasgos señalados antes. Primero, son los jóvenes quienes experimentan mayores ganancias, y no a costa de los adultos, sino de los mayores. Segundo, si bien la segunda mitad del perfil exhibe formas análogas para ambos géneros, en la primera mitad, sin embargo, sus formas son estrictamente inversas. $Y$, tercero, tanto en valor absoluto como relativo, las ganancias experimentadas por los varones son superiores al saldo de las mujeres.

¿Cómo entender estas diferencias? Lo más sencillo es pensar que el perfil transversal (mitad superior de la figura) refleja directa o indirectamente los cambios experimentados por la pirámide poblacional, cuya sucesión en dientes de sierra es sensiblemente análoga para hombres y mujeres. Mientras que, en cambio, el perfil longitudinal (mitad inferior del gráfico) reproduce con mucha fidelidad los cambios debidos al ciclo vital (curso de vida de cada cohorte). $\mathrm{Y}$ es sabido que, durante la etapa de crianza, los cursos vitales de las mujeres difieren sobremanera de los masculinos, cuando no los invierten claramente.

Respecto al caso que nos ocupa, el ciclo vital aparece asociado al transcurso de la carrera ocupacional, tal como se manifiesta en el ejemplo masculino, carente de la incidencia de sucesos como la nupcialidad y la maternidad, que configuran la carrera femenina. Durante la primera mitad del curso de vida de los hombres (perfil longitudinal masculino), los ingresos al mercado de trabajo superan claramente a las salidas. Muy fuertemente al principio (aunque no de golpe desde un comienzo, por efecto de la escolaridad tardía en la enseñanza superior), gradualmente después, en suave línea descendente. $\mathrm{Y}$ en cuanto se cruza el turning point de la plena ocupación (al cruzar el umbral de los cuarenta y cinco años), las salidas comienzan a superar a los tardíos ingresos, por lo que la curva inicia una pendiente descendente cada vez más pronunciada.

Este es el modelo canónico de ciclo vital esperable, y mal pueden ajustarse a él los perfiles transversales. Por el contrario, incluso lo desfiguran. Por ejemplo, a partir de datos transversales, suele decirse que, puesto que se retrasa la edad inicial de entrada al trabajo y, simultáneamente, se adelanta la edad terminal de salida por retiro y jubilación, el período activo de vida ocupada se estaría acortando doblemente de manera sensible. Pero esto es una falacia transversal, sólo desmentible con series longitudinales suficientemente largas. La cohorte que ahora está adelantando su retirada anticipada del trabajo inició su actividad ocupacional a edades muy tempranas: muy anteriores, en cualquier caso, a las que ahora manifiestan las cohortes que la inician. $Y$, paralelamente, la cohorte que ahora ingresa tardiamente al empleo es probable que no acepte, en el futuro, retirarse tan tempranamente. En cualquier caso, es una falacia transversal inventarse un modelo de carrera 
ocupacional hecho con retazos de cohortes diferentes, cuyos respectivos ciclos de vida son intransferibles e irrepetibles.

Por eso, nada mejor que las curvas longitudinales para registrar el efecto del cambio social sobre el curso de vida de las personas. En la figura 3 aparecen tres perfiles sucesivos de variación del empleo femenino, separados

\section{FIGURA 3}

Evolución longitudinal del empleo femenino

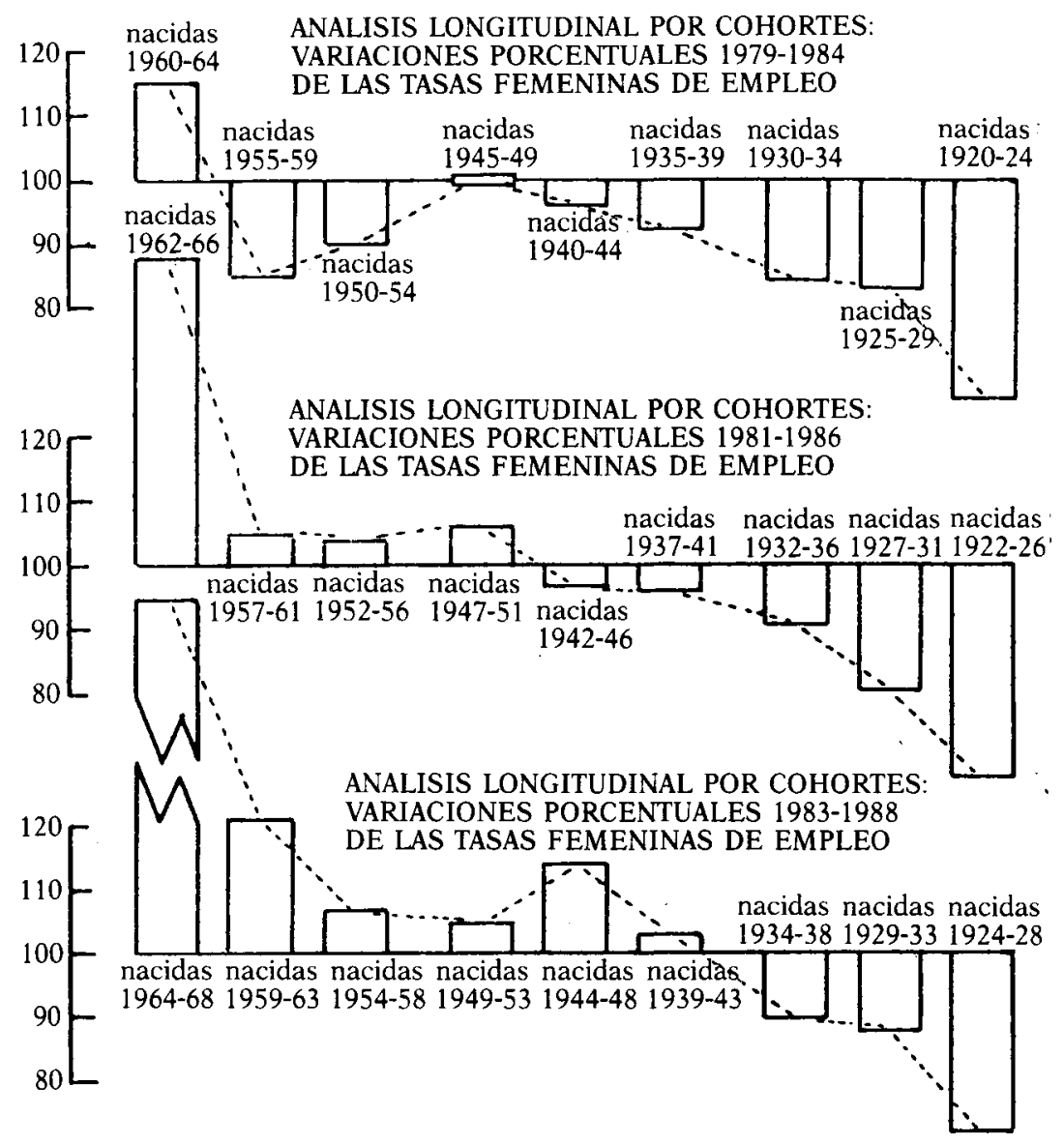

Fuente: Tabla 2. 
entre sí por muy pocos años. El superior corresponde a la fase final de la caída del empleo (variación de 1979 a 1984), el intermedio al punto central de inflexión (variación de 1981 a 1986) y el inferior a los momentos iniciales de reactivación del empleo (variación de 1983 a 1988). Puesto que en los tres casos la metodología es longitudinal, podemos comparar los cambios experimentados en un lapso de tiempo breve pero crucial.

Respecto a la magnitud absoluta de los cambios, cabe notar que las ganancias experimentadas por las últimas curvas son muy significativas. Si en el lustro 79-84 sólo un grupo ganaba y siete experimentaban pérdidas, en el lustro 83.88 los seis grupos iniciales ganan, y en muy gran medida, mientras sólo los tres terminales pierden, en buena lógica del ciclo vital (y, aún eso, en mucha menor medida que en las dos curvas previas).

Pero lo más llamativo (por la importancia que parece llamado a tener, y que ahora sólo podemos sospechar) es el cambio espectacular que, en estos años, se produce en la pauta femenina del ciclo vital. En la primera curva (79-84) todavía se produce lo que ya vimos con la mitad inferior de la figura 2: la continuidad lineal del modelo canónico masculino de carrera ocupacional resulta rota, en el caso de la carrera femenina, por la retirada del trabajo a consecuencia de la nupcialidad y la maternidad, al pasar del grupo de edad de veinte a veinticuatro años al de veinticinco a veintinueve años de edad. En efecto, si bien en el primer bloque se experimentan ganancias equivalentes a las masculinas (como corresponde a chicas solteras que tras abandonar los estudios ingresan en el empleo), en el segundo bloque, a diferencia del caso masculino, que era donde se situaban las máximas ganancias, se produce en el caso femenino una neta pérdida sustancial (que se prolonga hasta el bloque siguiente, aunque ya con inferior magnitud). Pues bien, a consecuencia de este bache, el perfil femenino adopta la conocida forma en «V» (durante la primera mitad del ciclo vital de la mujer), que corresponde al tradicional valle de la retirada-reingreso por matrimonio, maternidad y crianza. De tal modo, durante el lustro 79-84, los cambios sociales producidos no lograron modificar esta pauta femenina de vigencia secular.

Pero si dirigimos ahora nuestra atención a las otras dos curvas longitudinales que componen la figura 3 , advertiremos que, por fin, esa pauta de retirada se quiebra: ya desde luego en 1981-86, e incluso más todavía en 1983-88. En ambos casos, en el segundo y tercer bloques ya no se producen pérdidas (correspondientes a mayores salidas del empleo que ingresos), sino ganancias: lo que no quiere decir que no siga habiendo retiradas por matrimonio-maternidad sino que tales retiradas se ven netamente superadas por el ingreso al empleo procedente de la inactividad, el desempleo o la escolaridad. Es verdad que la forma de la curva sigue siendo cóncava, sin esa convexidad descendente del canon masculino; pero ya con linealidad positiva, de cifras de ganancia neta.

Cabe, pues, registrar el suceso para la historia del mercado español de 
trabajo: entre 1981 y 1986 se produjo un cambio dramático en la pauta secular del empleo femenino. Hasta ese momento, las mujeres seguían retirándose de la actividad económica al casarse o tener hijos. Pero, desde entonces, las nuevas cohortes de españolas ya no reproducen ese modelo, heredado como pauta de las generaciones previas, sino que, antes al contrario, y de forma innovadora, parecen capaces de simultanear nupcialidad y maternidad (muy reducidas y disminuidas, todo hay que decirlo) con empleo remunerado en la actividad económica: las jóvenes españolas están demostrando ser capaces de romper con el pasado y protagonizar el cambio.

En todo caso, las pruebas aportadas hasta ahora pueden parecer insuficientemente convincentes. Al fin y al cabo, los datos de la tabla 2, en los que se basa la figura 3 , no son puramente longitudinales, sino de técnica mixta: si bien el perfil que dibujan no es transversal, tampoco puede considerarse longitudinal más que como reconstrucción de un perfil imaginario, compuesto por retazos longitudinales procedentes de cohortes distintas, solapadamente superpuestas. En consecuencia, para suplir su rusticidad, se hace preciso reconstruir de verdad los ciclos vitales efectivos de cohortes generacionales completas.

En la tabla 3 se contienen los datos de la tasa femenina de actividad económica (procedentes de la serie histórica de la Encuesta de Población Activa, homogeneizada por Isabel Agüero y Carmen de Miguel), organizados de acuerdo a las dos dimensiones del esquema que aparecía en la figura 1: cohortes de nacimiento y grupos de edad. Podrá advertirse que todas las cohortes tradicionales exhiben la pauta de retirada-reingreso de la actividad por matrimonio, maternidad y crianza. En efecto, paralelamente a los varones de su edad, su tasa asciende en las fases iniciales hasta un máximo situado en el grupo de veinte a veinticuatro años, para desde allí descender conforme se producen las bodas y los nacimientos. El fondo de la "V》 del valle de retirada-reingreso por crianza puede situarse en el grupo de treinta a treinta y cuatro años de edad, como sucede con las cohortes más primitivas y prolíficas, o en el de veinticinco a veintinueve años de edad, como sucede con las más recientes y controladoras de su natalidad. A partir de ahí, conforme el hijo menor alcanza la edad de escolaridad obligatoria, se produce un modesto reingreso en la actividad económica.

Pero esta pauta tradicional es rota por la cohorte de mujeres nacidas entre 1957 y 1961, primeras en no hacer aparente la retirada por crianza (lo que podría implicar una discontinuidad histórica). Al pasar del grupo de los veinte a veinticuatro años hasta el de los veinticinco a veintinueve años de edad, lejos de reducir su tasa de actividad (como hasta entonces habían hecho todas las cohortes predecesoras), por el contrario la incrementan, pasando a dibujar una trayectoria de actividad comparable a la masculina.

Estos extraordinarios cambios de la actividad femenina quedan claramente reflejados en la figura 4 , donde aparecen representadas tres cohortes de 


\section{TABLA 3}

Análisis longitudinal de la evolución de la tasa femenina de actividad económica

\begin{tabular}{|c|c|c|c|c|c|c|c|c|c|c|}
\hline & & $\begin{array}{c}\text { obortes } \\
\text { mujer }\end{array}$ & & & $\begin{array}{c}16-19 \\
\text { años }\end{array}$ & $\begin{array}{c}20-24 \\
\text { años }\end{array}$ & $\begin{array}{l}25-29 \\
\text { años }\end{array}$ & $\begin{array}{l}30-34 \\
\text { años }\end{array}$ & $\begin{array}{l}35-39 \\
\text { años }\end{array}$ & $\begin{array}{l}40-44 \\
\text { años }\end{array}$ \\
\hline Nacid & & entre: & & & & & & & & \\
\hline $\begin{array}{l}1940 \\
1941 \\
1942 \\
1943 \\
1944\end{array}$ & $\begin{array}{l}y \\
y \\
y \\
y \\
y\end{array}$ & $\begin{array}{l}1944 \\
1945 \\
1946 \\
1947 \\
1948\end{array}$ & $\begin{array}{l}\ldots \\
\cdots \\
\cdots \\
\cdots \\
\cdots\end{array}$ & $\begin{array}{l}\ldots \\
\ldots \\
\ldots \\
\ldots \\
\cdots\end{array}$ & & $\begin{array}{l}34,49 \\
47,26 \\
46,27 \\
47,82 \\
49,74\end{array}$ & $\begin{array}{l}26,56 \\
26,70 \\
27,80 \\
29,92 \\
33,28\end{array}$ & $\begin{array}{l}27,30 \\
26,16 \\
26,51 \\
28,22 \\
29,68\end{array}$ & $\begin{array}{l}28,85 \\
29,08 \\
28,22 \\
30,00 \\
30,17\end{array}$ & $\begin{array}{l}28,94 \\
30,31 \\
29,66 \\
36,26 \\
37,47\end{array}$ \\
\hline $\begin{array}{l}1945 \\
1946 \\
1947 \\
1948 \\
1949\end{array}$ & $\begin{array}{l}y \\
y \\
y \\
y \\
y\end{array}$ & $\begin{array}{l}1949 \\
1950 \\
1951 \\
1952 \\
1953\end{array}$ & $\begin{array}{l}\cdots \\
\cdots \\
\cdots \\
\cdots \\
\cdots\end{array}$ & $\begin{array}{l}\cdots \\
\cdots \\
\cdots \\
\cdots \\
\cdots\end{array}$ & $\begin{array}{l}45,63 \\
46,15 \\
45,14 \\
45,02 \\
43,11\end{array}$ & $\begin{array}{l}49,70 \\
48,62 \\
49,75 \\
53,12 \\
59,10\end{array}$ & $\begin{array}{l}35,01 \\
34,39 \\
35,10 \\
36,69 \\
37,68\end{array}$ & $\begin{array}{l}29,66 \\
30,38 \\
31,47 \\
34,09 \\
37,84\end{array}$ & $\begin{array}{l}31,41 \\
33,09 \\
34,49 \\
40,08 \\
42,95\end{array}$ & \\
\hline $\begin{array}{l}1950 \\
1951 \\
1952 \\
1953 \\
1954\end{array}$ & $\begin{array}{l}y \\
y \\
y \\
y \\
y\end{array}$ & $\begin{array}{l}1954 \\
1955 \\
1956 \\
1957 \\
1958\end{array}$ & $\begin{array}{l}\cdots \\
\cdots \\
\cdots \\
\cdots \\
\cdots\end{array}$ & $\begin{array}{l}\cdots \\
\cdots \\
\cdots \\
\cdots \\
\cdots\end{array}$ & $\begin{array}{l}44,16 \\
43,30 \\
43,92 \\
45,11 \\
47,71\end{array}$ & $\begin{array}{l}58,19 \\
55,01 \\
53,96 \\
54,41 \\
54,62\end{array}$ & $\begin{array}{l}40,44 \\
42,06 \\
43,61 \\
47,39 \\
49,89\end{array}$ & $\begin{array}{l}38,72 \\
40,43 \\
45,32 \\
51,15 \\
51,56\end{array}$ & & \\
\hline $\begin{array}{l}1955 \\
1956 \\
1957 \\
1958 \\
1959\end{array}$ & $\begin{array}{l}y \\
y \\
y \\
y \\
y\end{array}$ & $\begin{array}{l}1959 \\
1960 \\
1961 \\
1962 \\
1963\end{array}$ & $\begin{array}{l}\cdots \\
\cdots \\
\cdots \\
\cdots \\
\cdots\end{array}$ & $\begin{array}{l}\cdots \\
\cdots \\
\cdots \\
\cdots \\
\cdots\end{array}$ & $\begin{array}{l}47,46 \\
44,66 \\
42,51 \\
41,19 \\
38,28\end{array}$ & $\begin{array}{l}55,16 \\
55,28 \\
55,79 \\
56,41 \\
56,35\end{array}$ & $\begin{array}{l}51,91 \\
53,82 \\
56,83 \\
61,66 \\
61,88\end{array}$ & & & \\
\hline $\begin{array}{l}1960 \\
1961 \\
1962 \\
1963 \\
1964\end{array}$ & $\begin{array}{l}y \\
y \\
y \\
y \\
y\end{array}$ & $\begin{array}{l}1964 \\
1965 \\
1966 \\
1967 \\
1968\end{array}$ & $\begin{array}{l}\ldots \\
\ldots \\
\cdots \\
\ldots \\
\ldots\end{array}$ & $\begin{array}{l}\ldots \\
\ldots \\
\ldots \\
\ldots \\
\ldots\end{array}$ & $\begin{array}{l}41,30 \\
38,78 \\
38,19 \\
37,13 \\
34,92\end{array}$ & $\begin{array}{l}55,81 \\
54,42 \\
55,86 \\
61,73 \\
63,31\end{array}$ & & & & \\
\hline
\end{tabular}

Fuentes: De 1964 a 1985, De Miguel y Agüero (1986); de 1986 a 1988, Encuesta de Población Activa, cuarto trimestre.

mujeres muy próximas en el tiempo entre sí (puesto que están separadas por lapsos de sólo cinco años), pero que, sin embargo, exhiben pautas de actividad no sólo diferentes sino, sobre todo, representativas de etapas distintas, cuya acelarada sustitución evolutiva marca no sólo la intensidad, sino también la velocidad del cambio.

La primera cohorte (nacidas de 1947 a 1951) es una de las últimas que todavía sitúan su etapa de más intensa retirada por crianza en el grupo de treinta a treinta y cuatro años de edad. La segunda (nacidas de 1952 a 1956) 


\section{FIGURA 4}

Evolución longitudinal de la tasa femenina de actividad

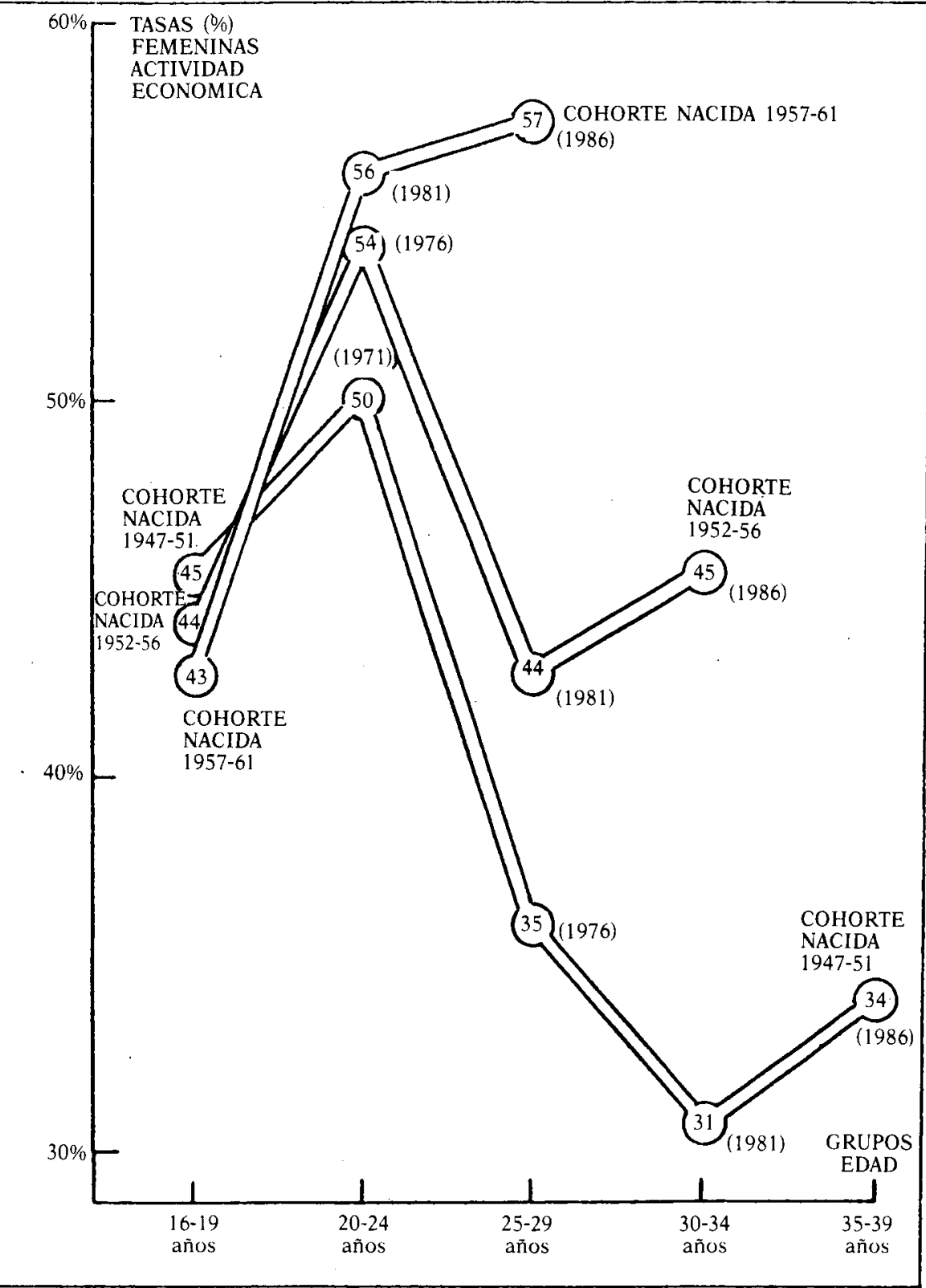

FUENTE: Tabla 3. 
es la primera que ya muy claramente concentra su retirada por crianza en tan sólo el grupo de veinticinco a veintinueve años de edad (puesto que en el siguiente grupo de edad, el de treinta a treinta y cuatro años, ya se produce un claro incremento). Y la tercera (nacidas de 1957 a 1961) se distingue y singulariza por ser la primera cohorte femenina que ya no experimenta retirada de la actividad económica por matrimonio y maternidad: al pasar del grupo veinte-veinticuatro al grupo veinticinco-veintinueve años, lejos de disminuir su tasa, como era la regla hasta ellas, la incrementan, introduciendo así una nueva pauta femenina que, de consolidarse, podrán reproducir todas las demás cohortes posteriores que les sigan.

En todo caso, el concepto de actividad económica es muy discutible, por cuanto se basa en la autopercepción subjetiva del encuestado. Por tanto, las demostraciones apoyadas tan sólo en sus datos no parecen excesivamente concluyentes. En consecuencia, para confirmar lo señalado hasta aquí, conviene registrarlo también con otros indicadores distintos y más fiables. En la tabla 4 aparecen las series longitudinales de ocupación femenina (medida en tasas sobre la base poblacional), tal y como aparecen en la tesis inédita de Garrido Medina, seleccionadas por lapsos lustrales. Y en la tabla 5 su ampliación a todos los valores anuales para un período más reducido.

\section{TABLA 4}

Análisis longitudinal del empleo femenino: tasas absolutas de ocupación por cohortes en periodos lustrales

\begin{tabular}{|c|c|c|c|c|c|c|c|c|c|}
\hline \multicolumn{4}{|c|}{$\begin{array}{l}\text { Cohortes } \\
\text { de mujeres }\end{array}$} & $\begin{array}{l}16-19 \\
\text { años }\end{array}$ & $\begin{array}{l}20-24 \\
\text { años }\end{array}$ & $\begin{array}{l}25-29 \\
\text { años }\end{array}$ & $\begin{array}{l}30-34 \\
\text { años }\end{array}$ & $\begin{array}{l}35-39 \\
\text { años }\end{array}$ & $\begin{array}{l}40.44 \\
\text { años }\end{array}$ \\
\hline \multicolumn{10}{|c|}{ Nacidas entre: } \\
\hline 1942 & $\mathrm{y}$ & 1946 & $\ldots$ & & 45,0 & 27,4 & 26,3 & 27,2 & 26,5 \\
\hline 1947 & $y$ & 1951 & $\ldots \quad \ldots$ & 40,5 & 47,9 & 34,2 & 28,4 & 30,2 & \\
\hline 1952 & $y$ & 1956 & $\ldots \quad \ldots$ & 40,9 & 50,5 & 35,6 & 36,9 & & \\
\hline 1957 & $\mathrm{y}$ & 1961 & $\ldots \quad \ldots$ & 36,3 & 38,0 & 39,8 & & & \\
\hline 1962 & $y$ & 1966 & $\ldots \quad \ldots$ & 19,8 & 29,3 & & & & \\
\hline 1967 & $\mathrm{y}$ & 1971 & $\ldots \quad \ldots$ & 13,5 & & & & & \\
\hline
\end{tabular}

Nota: La tasa absoluta de ocupación es el porcentaje de personas ocupadas sobre el total poblacional de cada grupo de edad.

FuENTE: Garrido Medina (1989), p. 388. 


\section{TABLA 5}

Análisis longitudinal del empleo femenino: tasas absolutas de ocupación por cobortes en valores anuales

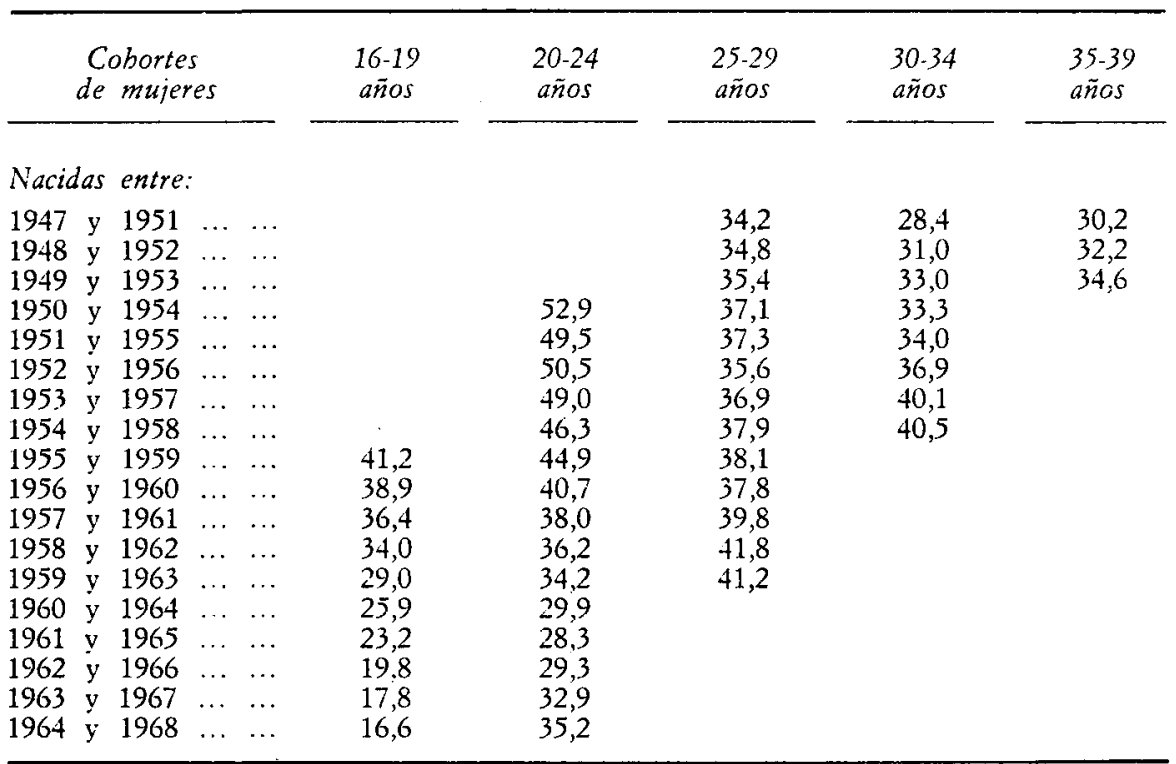

Fuente: Encuesta de Población Activa, cuartos trimestres.

Como podrá comprobarse, los datos longitudinales de ocupación femenina corroboran todo lo dicho acerca de la actividad económica: la cohorte nacida entre 1952 y 1956 es la primera que sitúa su mínimo por retirada del empleo en el grupo de veinticinco a veintinueve años de edad (en vez de hacerlo en el de treinta a treinta y cuatro años, como todas las cohortes previas), y la cohorte nacida entre 1957 y 1961 es la primera que ya no se retira del empleo al pasar del grupo de veinte a veinticuatro años (edad en que predomina la soltería y, por tanto, la predisposición a la participación laboral) al de veinticinco a veintinueve años de edad (donde ya predomina el matrimonio y la crianza, costosamente compatibles con la participación laboral).

Ello queda gráficamente representado en la figura 5, donde se reflejan las tasas absolutas de ocupación a edades iniciales en tres cohortes femeninas casi sucesivas (puesto que sus respectivos lustros de nacimiento se ven separados por lapsos de sólo dos años). Podrá captarse a simple vista el intenso cambio femenino experimentado en tan sólo cuatro años (y cambio objetivo, de empleo real; no de la mera percepción subjetiva de la actividad): de una cohorte cuya carrera ocupacional describía una pendiente francamente descen- 


\section{FIGURA 5}

Evolución longitudinal de la tasa femenina de ocupación absoluta

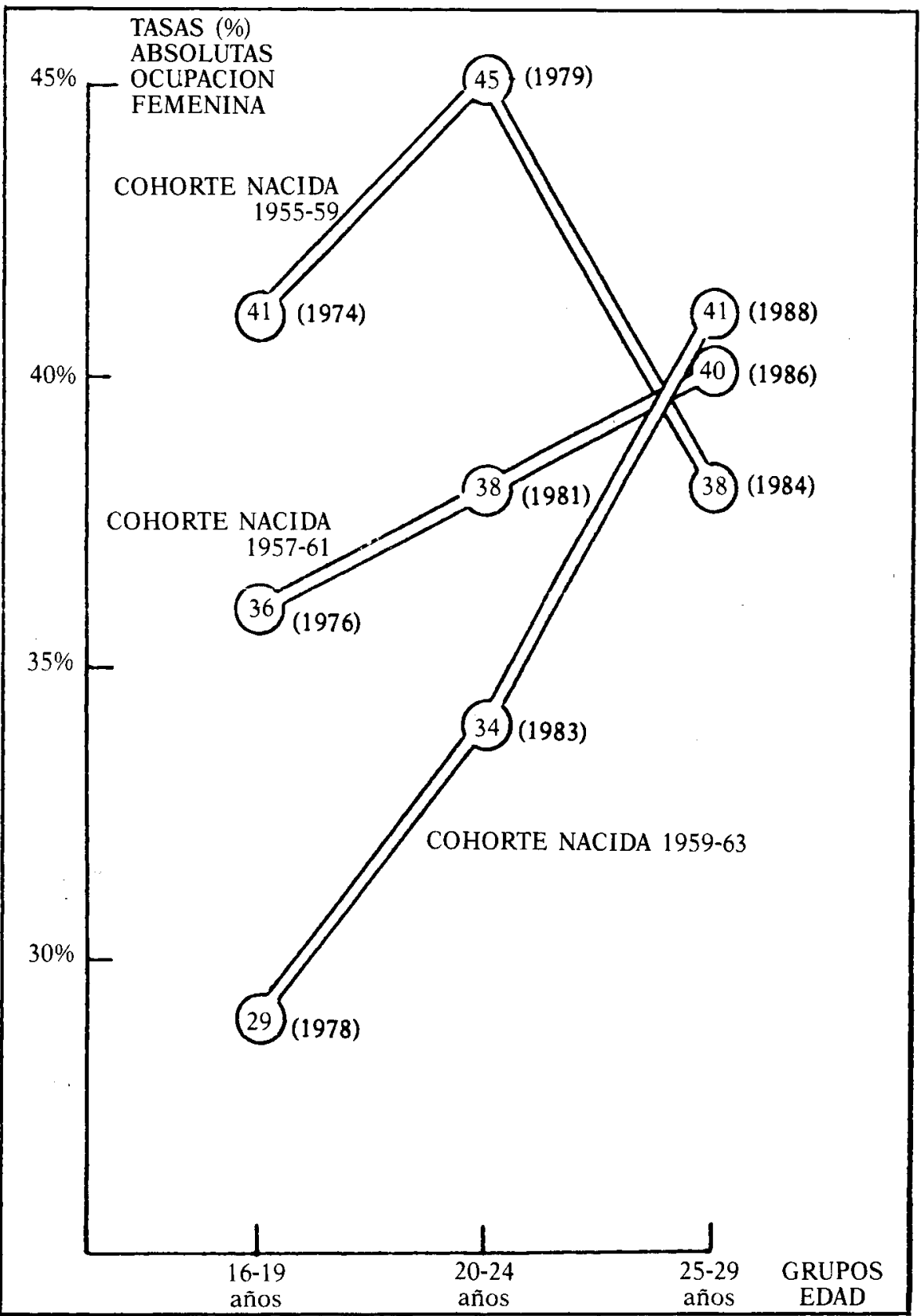

FUENTE: Tabla 5. 
dente (la de nacidas de 1955 a 1959), como corresponde a pautas femeninas donde trabajaba casi sólo la soltera, se ha pasado a otra cohorte cuya carrera ocupacional exhibe una clara senda ascendente (la de nacidas de 1959 a 1963), análoga a la pauta masculina.

¿Qué factores pudieron provocar tan sustanciales transformaciones en el curso vital de estas generaciones? Si aplicamos cuanto se desprende del análisis esbozado al comienzo de este escrito (estratificación por cohortes), cabrá interpretar que los factores desencadenantes de un cambio femenino tan espectacular han debido ser tanto exógenos como endógenos. Entre los primeros, claro está, aparece ante todo la coyuntura histórica y económica: tanto por lo que hace al tiempo en que estas cohortes iniciaron su curso vital (la socialización material y cultural impartida durante el desarrollismo difería sobremanera de la vigente durante la posguerra nacionalcatólica y subdesarrollada) como, sobre todo, al tiempo en que iniciaron s̀u inserción en la vida adulta (la transición política a la democracia y la crisis económica internacional, desencadenada con toda violencia durante la segunda mitad de la década de los setenta y la primera de los ochenta, impidió que las jóvenes se siguieran casando en la misma medida, obligándolas a luchar por su vida mediante el empleo remunerado; y ello tanto más para las pocas que lograban casarse, dado que con un solo ingreso salarial ya no hay hoy apenas hogar que se mantenga).

Pero no puede olvidarse tampoco el efecto producido por los propios factores endógenos a las cohortes consideradas. Ante todo, por supuesto, la escolaridad: las cohortes de mujeres nacidas durante los últimos cincuenta recibieron una escolarización considerablemente más prolongada que todas sus antecesoras, con notable diferencia. En consecuencia, dado que las tasas de actividad y ocupación son muy sensibles al nivel de estudios (especial. mente entre las mujeres casadas), no ha de extrañar en absoluto que estas cohortes desplieguen una carrera ocupacional enteramente nueva.

Pero entre los factores endógenos hay otro, el del tamaño relativo de las cohortes, que no parece conveniente menospreciar. Puede que, como subraya la sociología de la edad (según quedó apuntado al comienzo), la invisible influencia de este factor sea mayor de lo que cabría sospechar. Para advertirlo, nada mejor que considerar al respecto la figura 6 (basada en los datos de las tablas 6 y 7 ), donde se refleja el paralelo que se establece entre la evolución del tamaño relativo de las cohortes femeninas (cuando atraviesan la frontera de los veinticinco años de edad) y la evolución de las variaciones porcentuales que sufre su tasa de actividad económica al pasar del grupo de edad de veinte a veinticuatro años al de veinticinco a veintinueve años (es decir, al terminar de atravesar la frontera de los veinticinco años de edad).

Como podrá comprobarse, cuando las cohortes disminuyen de tamaño (como entre 1971 y 1977) se acentúa la intensidad de la retirada del empleo al sobrepasar los veinticinco años (como desde 1973 hasta 1976). Y viceversa, 


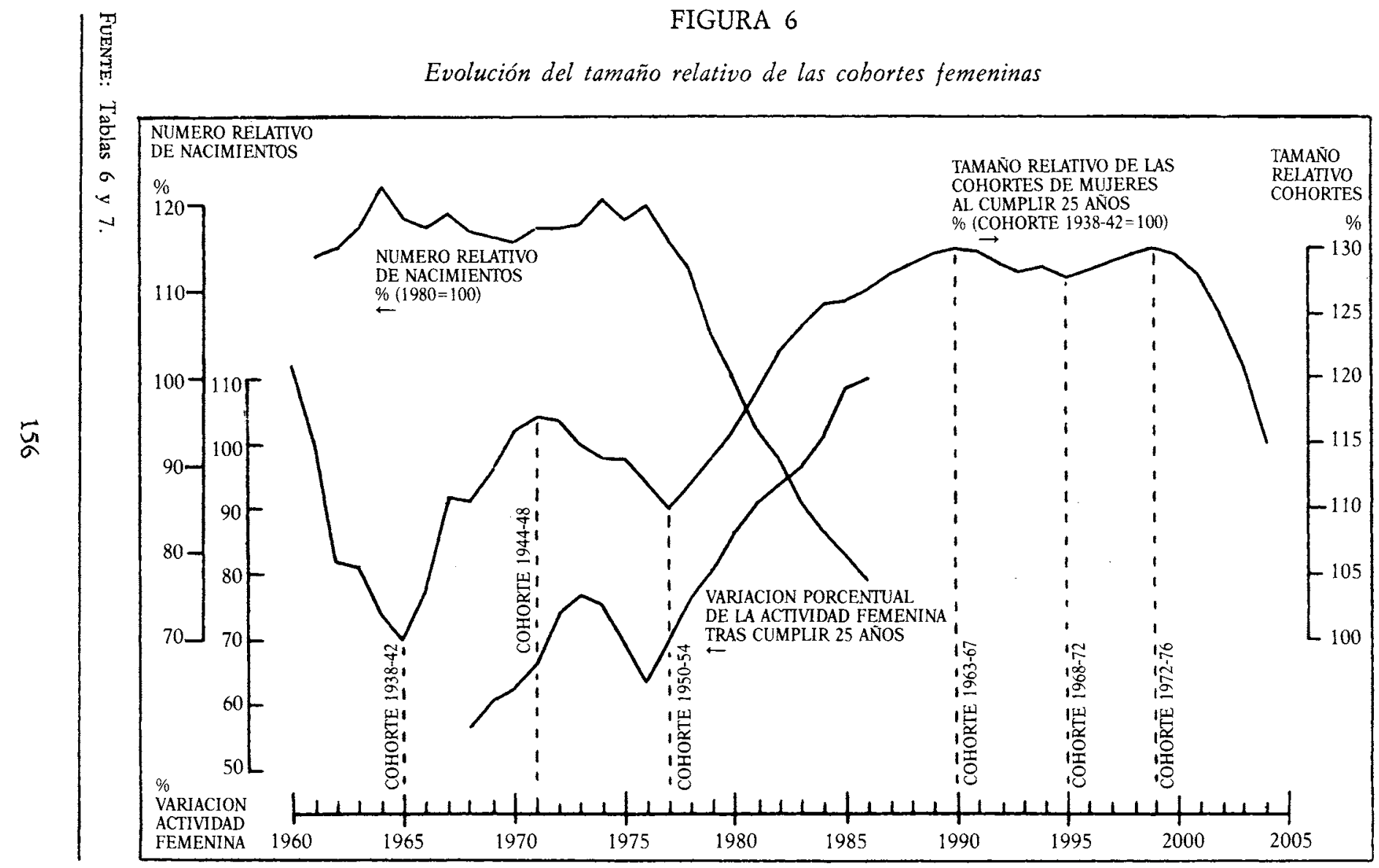




\section{TABLA 6}

Tamaño relutivo en origen de las cobortes de mujeres cuando la coborte atraviesa el umbral (turning point) de los veinticinco años

\begin{tabular}{|c|c|c|c|c|c|c|c|}
\hline $\begin{array}{c}\text { Coborte } \\
\text { mujeres } \\
\text { nacidas } \\
\text { entre } \\
(1)\end{array}$ & $\begin{array}{l}\text { Tamaño } \\
\text { absoluto } \\
\text { mujeres } \\
\text { nacidas } \\
\text { (miles) } \\
\text { (2) }\end{array}$ & $\begin{array}{c}\text { Tamaño } \\
\text { relativo } \\
(90) \\
\text { coborte } \\
(1938.42 \\
=100) \\
(3)\end{array}$ & $\begin{array}{c}\text { Año en } \\
\text { donde } \\
\text { cumplen } \\
25 \text { años } \\
\text { (4) }\end{array}$ & $\begin{array}{c}\text { Coborte } \\
\text { mujeres } \\
\text { nacidas } \\
\text { entre } \\
\text { (1) }\end{array}$ & $\begin{array}{c}\text { Tamaño } \\
\text { absoluto } \\
\text { mujeres } \\
\text { nacidas } \\
\text { (miles) } \\
\text { (2) }\end{array}$ & $\begin{array}{c}\text { Tamaño } \\
\text { relativo } \\
\text { (\%) } \\
\text { coborte } \\
(1938-42 \\
=100) \\
(3)\end{array}$ & $\begin{array}{c}\text { Año en } \\
\text { donde } \\
\text { cumplen } \\
25 \text { años } \\
\text { (4) }\end{array}$ \\
\hline $1933-37$ & 1.515 & 120,9 & 1960 & $1958-62$ & 1.578 & 125,9 & 1985 \\
\hline $1934-38$ & 1.436 & 114,6 & 1961 & $1959-63$ & 1.585 & 126,5 & 1986 \\
\hline $1935-39$ & 1.329 & 106,1 & 1962 & $1960-64$ & 1.606 & 128,2 & 1987 \\
\hline $1936-40$ & 1.326 & 105,8 & 1963 & $1961-65$ & 1.614 & 128,8 & 1988 \\
\hline $1937-41$ & 1.273 & 101,6 & 1964 & $1962-66$ & 1.622 & 129,5 & 1989 \\
\hline $1938-42$ & 1.253 & 100,0 & 1965 & $1963-67$ & 1.633 & 130,3 & 1990 \\
\hline $1939-43$ & 1.301 & 103,8 & 1966 & 1964.68 & 1.632 & 130,3 & 1991 \\
\hline 1940.44 & 1.389 & 110,9 & 1967 & $1965-69$ & 1.616 & 129,0 & 1992 \\
\hline 1941.45 & 1.386 & 110,6 & 1968 & $1966-70$ & 1.609 & 128,4 & 1993 \\
\hline 1942.46 & 1.422 & 113,5 & 1969 & $1967-71$ & 1.610 & 128,5 & 1994 \\
\hline 1943.47 & 1.450 & 115,7 & 1970 & $1968-72$ & 1.606 & 128,2 & 1995 \\
\hline 1944.48 & 1.466 & 117,0 & 1971 & 1969.73 & 1.609 & 128,4 & 1996 \\
\hline 1945.49 & 1.465 & 116,9 & 1972 & 1970.74 & 1.621 & 129,4 & 1997 \\
\hline 1946.50 & 1.436 & 114,6 & 1973 & 1971.75 & 1.625 & 129,7 & 1998 \\
\hline 1947.51 & 1.427 & 113,9 & 1974 & 1972.76 & 1.630 & 130,1 & 1999 \\
\hline 1948.52 & 1.428 & 114,0 & 1975 & $1973-77$ & 1.624 & 129,6 & 2000 \\
\hline 1949.53 & 1.403 & 112,0 & 1976 & 1974.78 & 1.607 & 128,3 & 2001 \\
\hline 1950.54 & 1.392 & 110,1 & 1977 & $1975-79$ & 1.562 & 124,7 & 2002 \\
\hline 1951.55 & 1.408 & 112,4 & 1978 & $1976-80$ & 1.511 & 120,6 & 2003 \\
\hline $1952-56$ & 1.428 & 114,0 & 1979 & 1977.81 & 1.440 & 114,9 & 2004 \\
\hline 1953.57 & 1.456 & 116,2 & 1980 & $1978-82$ & 1.369 & 109.3 & 2005 \\
\hline $1854-58$ & 1.487 & 118,7 & 1981 & 1979.83 & 1.296 & 103,4 & 2006 \\
\hline 1955.59 & 1.523 & 121,6 & 1982 & $1980-84$ & 1.236 & 98,6 & 2007 \\
\hline $1956-60$ & 1.553 & 123,9 & 1983 & $1981-85$ & 1.182 & 94,3 & 2008 \\
\hline $1957-61$ & 1.574 & 125,6 & 1984 & $1982-86$ & 1.135 & 90,6 & 2009 \\
\hline
\end{tabular}

Notas: (1) Período quinquenal durante el que se produce el nacimiento de la cohorte.(2) Número de mujeres nacidas, en miles, durante el período quinquenal antecedente.-(3) Tamaño relativo, en porcentaje, de la cohorte de mujeres nacidas durante el período quinquenal antecedente (base del porcentaje: miles de nacidas durante el quinquenio 1938-42 igual a 100)-(4) Año central durante el cual, en promedio, el conjunto de de la cohorte atraviesa el umbral (turning point) de los 25 años de edad.

Fuente: Anuatio del Instituto Nacional de Estadística. 


\section{TABLA 7}

Variación de la tasa femenina de actividad económica, al cumplirse veinticinco años, y número absoluto y relativo de nacimientos

\begin{tabular}{|c|c|c|c|c|c|c|}
\hline $\begin{array}{c}\text { Coborte } \\
\text { mujeres } \\
\text { nacidas } \\
\text { entre }\end{array}$ & $\begin{array}{l}\text { Tasa de } \\
\text { actividad } \\
20-24 \\
\text { años } \\
\text { (A) }\end{array}$ & $\begin{array}{l}\text { Tasu de } \\
\text { actividad } \\
25-29 \\
\text { años } \\
\text { (B) }\end{array}$ & $\begin{array}{l}\text { Incremento } \\
\text { porcentual } \\
C=\frac{100 \mathrm{~B}}{\mathrm{~A}}\end{array}$ & $\begin{array}{l}\text { Año que } \\
\text { cumplen } \\
25 \text { años }\end{array}$ & $\begin{array}{l}\text { Miles de } \\
\text { nacidos } \\
\text { en año } \\
\text { referencia }\end{array}$ & $\begin{array}{l}\text { Número } \\
\text { relativo } \\
\text { nacimientos } \\
(1980= \\
100)\end{array}$ \\
\hline & & & & $\begin{array}{l}(1961) \\
(1962) \\
(1963) \\
(1964) \\
(1965) \\
(1966)\end{array}$ & $\begin{array}{l}646 \\
650 \\
662 \\
689 \\
668 \\
662\end{array}$ & $\begin{array}{l}114,3 \\
115,0 \\
117,2 \\
122,0 \\
118,2 \\
117,2\end{array}$ \\
\hline $\begin{array}{l}1940-44 \\
1941-45 \\
1942-46 \\
1943-47 \\
1944-48\end{array}$ & $\begin{array}{l}\overline{47,26} \\
46,27 \\
47,82 \\
49,74\end{array}$ & $\begin{array}{l}26,56 \\
26,70 \\
27,80 \\
29,92 \\
33,28\end{array}$ & $\begin{array}{l}- \\
56,50 \\
60,08 \\
62,57 \\
66,91\end{array}$ & $\begin{array}{l}1967 \\
1968 \\
1969 \\
1970 \\
1971\end{array}$ & $\begin{array}{l}672 \\
659 \\
658 \\
656 \\
665\end{array}$ & $\begin{array}{l}118,9 \\
116,6 \\
116,5 \\
116,1 \\
117,7\end{array}$ \\
\hline $\begin{array}{l}1945-49 \\
1946-50 \\
1947.51 \\
1948.52 \\
1949.53\end{array}$ & $\begin{array}{l}49,70 \\
48,62 \\
49,75 \\
53,12 \\
59,10\end{array}$ & $\begin{array}{l}35,01 \\
34,39 \\
35,10 \\
36,69 \\
37,68\end{array}$ & $\begin{array}{l}70,44 \\
70,73 \\
70,55 \\
69,07 \\
63,76\end{array}$ & $\begin{array}{l}1972 \\
1973 \\
1974 \\
1975 \\
1975\end{array}$ & $\begin{array}{l}665 \\
666 \\
682 \\
669 \\
677\end{array}$ & $\begin{array}{l}117,7 \\
117,9 \\
120,7 \\
118,4 \\
119,8\end{array}$ \\
\hline $\begin{array}{l}1950.54 \\
1951.55 \\
1952.56 \\
1953.57 \\
1954.58\end{array}$ & $\begin{array}{l}58,19 \\
55,01 \\
53,96 \\
54,41 \\
54,62\end{array}$ & $\begin{array}{l}40,44 \\
42,06 \\
43.61 \\
47,39 \\
49,89\end{array}$ & $\begin{array}{l}69,50 \\
76,46 \\
80,82 \\
87,10 \\
91,34\end{array}$ & $\begin{array}{l}1977 \\
1978 \\
1979 \\
1980 \\
1981\end{array}$ & $\begin{array}{l}656 \\
637 \\
593 \\
565 \\
532\end{array}$ & $\begin{array}{r}116,1 \\
112,7 \\
105,0 \\
100,0 \\
94,2\end{array}$ \\
\hline $\begin{array}{l}1955-59 \\
1956-60 \\
1957-61 \\
1958-62 \\
1959-63\end{array}$ & $\begin{array}{l}55,16 \\
55,28 \\
55,79 \\
56,41 \\
56,35\end{array}$ & $\begin{array}{l}51,91 \\
53,82 \\
56,83 \\
61,66 \\
61,88\end{array}$ & $\begin{array}{r}94,11 \\
97,36 \\
101,86 \\
109,31 \\
109,81\end{array}$ & $\begin{array}{l}1982 \\
1983 \\
1984 \\
1985 \\
1986\end{array}$ & $\begin{array}{l}516 \\
485 \\
466 \\
452 \\
435\end{array}$ & $\begin{array}{l}91,3 \\
85,8 \\
82,5 \\
80,0 \\
77,0\end{array}$ \\
\hline
\end{tabular}

Fuentes: De Miguel y Agüero (1986), EPA del INE y Anuario del INE.

cuando se incrementa el tamaño de las cohortes (como de 1965 a 1971, y a partir de 1977), la retirada del empleo disminuye (como a partir de 1976 ininterrumpidamente): y tanto llega a reducirse que, a partir de 1983, incluso se incrementa el empleo (al pasar del grupo veinte-veinticuatro al de veinticinco-veintinueve años), en vez de reducirse.

He aquí, pues, posible explicación adicional sobre las extraordinarias mutaciones que, mediante análisis longitudinal, hemos podido rastrear en las 
pautas ocupacionales de las españolas. El que, como hemos visto, las cohortes nacidas después de 1957 protagonicen un giro copernicano en la carrera laboral femenina, puede ser debido, entre otras razones, a que son las primeras generaciones procedentes del baby-boom (o explosión de la natalidad): la tensión maltusiana de su propia superpoblación habría provocado el aumento de su presión sobre el mercado de trabajo. En función de esta hipótesis, y tal como puede interpretarse la figura 6 , parece darse una cierta asociación positiva (o relación directamente proporcional) entre el tamaño de las cohortes femeninas y su participación laboral durante el grupo de edad que menos propenso es a ella: el de veinticinco a veintinueve años, que es donde se concentran las bodas y el nacimiento de los primeros hijos.

En efecto, si los veinticinco años son un turning point determinante de la trayectoria vital de las mujeres, es porque allí se produce la disyuntiva entre su carrera ocupacional (laboral o profesional) y su carrera familiar (matrimonial y maternal). En el grupo de veinte a veinticuatro años de edad, la mayoría de las mujeres están solteras sin hijos $\mathrm{y}$, por tanto, pueden trabajar sin problemas. En cambio, en el grupo de veinticinco a veintinueve años de edad, ya se ha casado la mayoría, y está criando sus primeros hijos; en consecuencia, experimenta muchas dificultades para compaginar trabajo y maternidad, por lo que se incrementa sobremanera la probabilidad de que se reduzca su participación laboral.

Por ello, si la variación de la tasa de actividad económica, al sobrepasar los veinticinco años, invierte su signo, pasando del descenso (intensificación de la retirada) al alza (reducción de la retirada, hasta el punto de incrementarse la participación laboral), puede ser debido, entre otras causas, tanto a la creciente extensión de la doble carrera (simultaneando participación laboral y maternidad) como a la disminución sostenida de la nupcialidad y la maternidad.

$Y$, en efecto, la figura 6 manifiesta la posible existencia de una relación negativa (o inversamente proporcional) entre la curva de la natalidad y la que registra la participación laboral: a partir de 1976, conforme desciende intensamente la natalidad, en análoga proporción asciende sostenidamente la participación laboral de las mujeres de veinticinco a veintinueve años respecto de las que tienen de veinte a veinticuatro años de edad.

En consecuencia, la figura 6 sugiere otra hipótesis adicional. Si el tamaño de las cohortes se asocia a su participación laboral, y si a su vez ésta resulta relacionada con la natalidad, ¿no habrá también una relación asociativa entre tamaño de cohortes y natalidad? Si las primers cohortes procedentes del babyboom inicial parecen haber sido portadoras de una especie de revolución laboral, capaz de absorber los efectos de su propia superpoblación, ¿no se habrá producido una consecuencia análoga sobre la fecundidad? ¿En qué medida la drástica reducción de nacimientos, que se produce a partir de 1976, se debe al incremento del tamaño de las nuevas generaciones de mujeres 
jóvenes? ¿Es, en suma, la natalidad inversamente proporcional al tamaño de las cohortes progenitoras, como la figura 6 parece manifestar?

\section{La proporción relativa de jóvenes}

Juan Antonio Fernández Cordón, en un penetrante análisis sobre el reciente ciclo demográfico español, basado en la metodología de las cohortes generacionales, comenta: «Situar el peso de la explicación en las generaciones nos permite buscar el origen profundo de los movimientos observados en épocas que pueden estar bastante alejadas del momento de observación, como en el caso de la llamada teoría de Easterlin» ${ }^{9}$. Y Cabré y Pujadas, en un sugestivo estudio longitudinal de la fecundidad catalana, concluyen también: «La máxima fecundidad la presentan, como para dar la razón a la teoría de Easterlin, precisamente las generaciones que fueron las más escasas al nacer» ${ }^{10}$.

Como es sabido, el modelo Easterlin interpreta la fecundidad efectiva de una generación dada como inversamente proporcional a su tamaño relativo ": su análisis es, por ello, coherente con el modelo de estratificación por cohortes que propone la sociología de la edad. Pues bien, el modelo Easterlin de ciclo demográfico nos aporta una posible interpretación de la revolución ocupacional que están experimentando las nuevas cohortes de españolas. Para ello basta considerar que si las mujeres incrementan su tasa de actividad y empleo, al atravesar el turning point de los veinticinco años, en vez de reducirla como hacían todas sus predecesoras, puede ser porque, de acuerdo al modelo Easterlin, se estén viendo obligadas, por su propia superpoblación, a reducir y posponer tanto su nupcialidad como su fecundidad.

En la figura 6 , donde se representa gráficamente el ciclo oscilatorio del tamaño relativo de las cohortes de mujeres que están atravesando la frontera de los veinticinco años, puede advertirse la proporcionalidad inversa que se establece entre el tamaño relarivo de una cohorte y su fecundidad consecuente. En efecto, los máximos y los mínimos del tamaño relativo de las cohortes están separados, precisamente, por un lapso de veintidós a veinticinco años. En 1965 atraviesa sus veinticinco años la cohorte de mínimo tamaño relativo: la nacida entre 1938 y 1942. Y veinticinco años despuès, en 1990, atravesará sus veinticinco años la cohorte de máximo tamaño relativo: la nacida entre 1963 y 1967. Adicionalmente, en 1977 estaba atravesando sus veinticinco

9 Véase Fernández Cordón (1986). La cita aparece en la p. 58 de la compilación de las Actas del Simposio Internacional sobre Tendencias demográticas y planificación económica (Mineco, 1986).

"Cabré y Pujadas (1987), p. 14.

$"$ Los tres textos fundamentales que jalonan las principales etapas de construcción del modelo Easterlin son: su texto pionero, Easterlin (1968); su formulación más acabada, Easterlin (1978), y su más reciente reformulación, donde responde a sus críticos e insiste en la inminencia de otro nuevo baby-boom, más intenso que el anterior: Easterlin (1987). 
años la cohorte cuyo tamaño relativo era el submínimo: la nacida desde 1950 hasta 1954. En consecuencia, veintidós años después, en 1999, estará atravesando sus veinticinco años la cohorte femenina cuyo tamaño relativo será el submáximo: la nacida entre 1972 y 1976.

Todo lo cual resulta particularmente interesante. En efecto, no sólo corrobora el axioma fundamental que es común al modelo de estratificación por cohortes y al modelo Easterlin (a saber, que la descendencia de una cohorte es inversamente proporcional a su tamaño relativo), sino que, además, confirma un interesante descubrimiento de Cabré y Pujadas, que no se halla previsto por el modelo Easterlin. Al analizar el comportamiento diferencial de las tasas de fecundidad por edad, en las distintas fases del ciclo demográfico, Cabré y Pujadas observan que, durante la fase inicial de un baby-boom, el tirón de la fecundidad lo protagonizan las mujeres mayores de veinticinco años, que culminan así una carrera reproductiva que se había visto pospuesta por la fase depresiva del ciclo cuando ellas eran más jóvenes. Y que, en cambio, a partir de la fase central del baby-boom y, sobre todo, durante su fase terminal, son las mujeres menores de veinticinco años las que toman la iniciativa, adelantando precozmente sus nupcias tempranas y su consiguiente fecundidad, por lo que, como consecuencia, durante la segunda mitad del baby-boom, los nacimientos habidos por mujeres de veinte a veinticuatro años supcran con creces a los tenidos por las de treinta a treinta y cuatro años, en contra de cuanto sucede durante los puntos más bajos del ciclo demográfico ${ }^{12}$.

Pues bien, este descubrimiento resulta igualmente corroborado por la figura 6. En efecto, el primer mínimo en el tamaño relativo de las cohortes de mujeres, que corresponde a la fase inicial del baby-boom, está separado veinticinco años del momento en que su abultada descendencia alcanzará su tamaño máximo. En cambio, el segundo submínimo, que corresponde a la tardía fase terminal del baby-boom, ya únicamente está separado del submáximo que alcanzará su descendencia por tan sólo veintidós años: señal de que durante la segunda mitad del baby-boom las bodas y los nacimientos se adelantaron tempranamente, con precocidad anterior a los veinticinco años.

Sin embargo, Easterlin no utiliza como indicador estratégico para su modelo el tamaño relativo de cohortes contiguas de mujeres, como hasta ahora se ha hecho aquí, sino algo relacionado pero bastante distinto, en realidad: la proporción de varones jóvenes respecto al número de varones adultos (expresada como porcentaje de aquéllos respecto a éstos). En la tabla 8 se transcriben los datos del propio Easterlin para el caso norteamericano. La lógica de este indicador es simple. Cuando la proporción relativa de jóvenes es demasiado elevada aparecen presiones maltusianas que, a través de una serie de variables intermedias (nivel de empleo, nivel salarial, coste de la vivienda, etc.), deprimen tanto la nupcialidad como la fecundidad. En consecuencia, las cohortes

${ }^{12}$ Cabré y Pujadas (1987), ob. cit., p. 12. 


\section{TABLA 8}

Estados Unidos: población masculina de quince a veintinueve años como porcentaje de la que tiene de treinta a sesenta y cuatro años

\begin{tabular}{|c|c|c|c|c|}
\hline & $A \tilde{n} o$ & $\begin{array}{c}\text { Varones } 15-29 \\
\text { (miles) }\end{array}$ & $\begin{array}{c}\text { Varones } 30-64 \\
\text { (miles) }\end{array}$ & $\begin{array}{l}\text { Razón (Co) } \\
15-29 / 30-64\end{array}$ \\
\hline \multicolumn{5}{|l|}{ Observado: } \\
\hline $\begin{array}{lll}1940 & \ldots & \ldots \\
1950 & \ldots & \ldots \\
1955 & \ldots & \ldots \\
1960 & \ldots & \ldots \\
1965 & \ldots & \ldots \\
1970 & \ldots & \ldots \\
1975 & \ldots & \ldots \\
\end{array}$ & $\begin{array}{llllll}\ldots & \ldots & \ldots & \ldots & \ldots & \ldots \\
\ldots & \ldots & \ldots & \ldots & \ldots & \ldots \\
\ldots & \ldots & \ldots & \ldots & \ldots & \ldots \\
\ldots & \ldots & \ldots & \ldots & \ldots & \ldots \\
\ldots & \ldots & \ldots & \ldots & \ldots & \ldots \\
\ldots & \ldots & \ldots & \ldots & \ldots & \ldots \\
\ldots & \ldots & \ldots & \ldots & \ldots & \ldots \\
\ldots & \ldots & \ldots & \ldots & \ldots & \ldots \\
\cdots & \ldots & \ldots & \ldots & \ldots & \ldots\end{array}$ & $\begin{array}{l}17.442 \\
17.216 \\
16.772 \\
17.794 \\
21.151 \\
25.262 \\
28.793\end{array}$ & $\begin{array}{l}27.664 \\
31.761 \\
33.781 \\
35.478 \\
36.295 \\
38.115 \\
38.908\end{array}$ & $\begin{array}{l}63,0 \\
54,4 \\
49,6 \\
50,2 \\
58,3 \\
66,3 \\
74,0\end{array}$ \\
\hline \multicolumn{5}{|l|}{ Proyectado: } \\
\hline $\begin{array}{llll}1980 & \ldots & \ldots \\
1985 & \ldots & \ldots \\
1990 & \ldots & \ldots \\
1995 & \ldots & \ldots \\
\end{array}$ & $\begin{array}{llllll}\ldots & \ldots & \ldots & \ldots & \ldots & \ldots \\
\ldots & \ldots & \ldots & \ldots & \ldots & \ldots \\
\ldots & \ldots & \ldots & \ldots & \ldots & \ldots \\
\ldots & \ldots & \ldots & \ldots & \ldots & \ldots \\
\ldots & \ldots & \ldots & \ldots & \ldots & \ldots\end{array}$ & $\begin{array}{l}30.426 \\
29.717 \\
27.626 \\
25.864\end{array}$ & $\begin{array}{l}42.184 \\
46.210 \\
50.585 \\
54.759\end{array}$ & $\begin{array}{l}72,1 \\
64,3 \\
54,6 \\
47,2\end{array}$ \\
\hline
\end{tabular}

Fuente: Easterlin (1987), p. 186.

que van naciendo reducen cada vez más su tamaño y, al cabo del tiempo, la proporción relativa de jóvenes desciende. Ahora bien, cuando esta proporción desciende demasiado se producen consecuencias inesperadas: las oportunidades de vida para los jóvenes mejoran tanto, dada su misma escasez, que, a través del incremento sostenido de su nivel relativo de rentas teales, tanto la nupcialidad como la fecundidad se adelantan e intensifican. En consecuencia, se produce un baby-boom que realimenta el círculo vicioso: en la tabla 8 pueden verse los bandazos del ciclo norteamericano, desde un 50 por 100 de jóvenes en 1955 hasta un 75 por 100 en 1975, así como la proyectada caída hasta el 45 por 100 en 1995.

¿Cuándo es demasiado elevada o demasiado baja la proporción relativa de jóvenes? ¿Puede existir algún criterio de normalidad? Dada la construcción del indicador de Easterlin (donde el numerador de varones jóvenes está compuesto por tres cohortes quinquenales, mientras el denominador de varones adultos lo está por siete), en condiciones ideales la proporción relativa de jóvenes debiera ser de 42,86 por 100 . Dada la existencia de mortalidad, que va diezmando progresivamente las cohortes, un buen criterio aproximado de estimación es el de 50 por 100 (dos adultos por cada joven): de las siete cohortes quinquenales adultas se supone diezmada una, restando seis para duplicar las tres de jóvenes. Así, con arreglo a este criterio simplista pero 
cómodo, puede decirse que hay superpoblación de jóvenes cuando su proporción sobrepasa el 50 por 100 ; y, análogamente, que habrá escasez relativa cuando descienda por debajo de esa cifra.

La tabla 9 es la directa traducción de la tabla 8 norteamericana al caso español. Parecerá, en principio, que la oscilación de nuestro ciclo es mucho menos elástica, dado que sólo fluctúa desde el 48 por 100 de jóvenes (máxima escasez: pleno empleo y baby-boom) hasta el 55 por 100 (máxima superpoblación: desempleo y baby-bust). Pero eso es debido a la naturaleza de la fuente estadística, que prescinde no sólo de los jóvenes de quince años, sino también de los que se hallan realizando su servicio militar. $Y$, para evitarlo, en las tablas 10 y 11 aparecen nuevos datos, extraídos de otras fuentes alternativas.

En los años sesenta, durante la fase central del baby-boom, la proporción relativa de jóvenes era mínima, con un 48 por 100 . Y durante los años ochenta, coincidiendo con el hiperdesempleo y el punto más bajo de la fecundidad, la proporción relativa de jóvenes se hace máxima, rozando el 63 por 100. ¿Cuándo se producirá el punto de inflexión del ciclo, cambiando la tendencia y comenzando a descender la proporción de jóvenes? Según la proyección de la tabla 11 , el número absoluto de jóvenes varones alcanzará su máximo en 1991-1992, pero no comenzará a descender claramente por debajo de los cinco millones hasta la segunda mitad de la década de los

\section{TABLA 9}

España: población masculina de dieciséis a veintinueve años (sin servicio militar) como porcentaje de la que tiene de treinta a sesenta y cuatro años

\begin{tabular}{|c|c|c|c|c|}
\hline & $A \tilde{n} o$ & $\begin{array}{c}\text { Varones 16-29 } \\
\text { (miles) }\end{array}$ & $\begin{array}{l}\text { Varones } 30-64 \\
\text { (miles) }\end{array}$ & $\begin{array}{l}\text { Razón (\%) } \\
16-29 / 30-64\end{array}$ \\
\hline \multicolumn{5}{|l|}{ Observado: } \\
\hline $\begin{array}{lll}1966 & \ldots & \ldots \\
1971 & \ldots & \ldots \\
1976 & \ldots & \ldots \\
1981 & \ldots & \ldots\end{array}$ & $\begin{array}{cccccc}\ldots & \ldots & \ldots & \ldots & \ldots & \ldots \\
\ldots & \ldots & \ldots & \ldots & \ldots & \ldots \\
\ldots & \ldots & \ldots & \ldots & \ldots & \ldots \\
\ldots & \ldots & \ldots & \ldots & \ldots & \ldots\end{array}$ & $\begin{array}{l}3.087,1 \\
3.206,9 \\
3.452,7 \\
3.780,2\end{array}$ & $\begin{array}{l}6.428,1 \\
6.637,0 \\
6.903,1 \\
7.338,6\end{array}$ & $\begin{array}{l}48,03 \\
48,32 \\
50,02 \\
51,51\end{array}$ \\
\hline \multicolumn{5}{|l|}{ Proyectado: } \\
\hline $\begin{array}{lll}1986 & \ldots & \ldots \\
1991 & \ldots & \ldots \\
1996 & \ldots & \ldots \\
2.001 & \ldots & \ldots\end{array}$ & $\begin{array}{llllll}\ldots & \ldots & \ldots & \ldots & \ldots & \ldots \\
\ldots & \ldots & \ldots & \ldots & \ldots & \ldots \\
\ldots & \ldots & \ldots & \ldots & \ldots & \ldots \\
\ldots & \ldots & \ldots & \ldots & \ldots & \ldots\end{array}$ & $\begin{array}{l}4.238,2 \\
4.440,3 \\
4.385,9 \\
3.991,6\end{array}$ & $\begin{array}{l}7.709,7 \\
8.065,1 \\
8.521,2 \\
8.976,2\end{array}$ & $\begin{array}{l}54,97 \\
55,06 \\
51,47 \\
44.47\end{array}$ \\
\hline
\end{tabular}

Fuente: De Miguel y Agüero (1986). 


\section{TABLA 10}

Proporción de jóvenes (varones, quince-veintinueve años) como porcentaje del numero de adultos (varones, treinta-sesenta y cuatro): España, 1965-84

\begin{tabular}{|c|c|c|c|}
\hline Año & $\begin{array}{c}\text { Proporción } \\
\text { jóvenes } \\
(\%)\end{array}$ & $A \tilde{n} o$ & $\begin{array}{c}\text { Proporción } \\
\text { jóvenes } \\
(0)\end{array}$ \\
\hline $\begin{array}{llllllll}1965 & \ldots & \ldots & \ldots & \ldots & \ldots & \ldots & \ldots \\
1966 & \ldots & \ldots & \ldots & \ldots & \ldots & \ldots & \ldots \\
1967 & \ldots & \ldots & \ldots & \ldots & \ldots & \ldots & \ldots \\
1968 & \ldots & \ldots & \ldots & \ldots & \ldots & \ldots & \ldots \\
1969 & \ldots & \ldots & \ldots & \ldots & \ldots & \ldots & \ldots\end{array}$ & $\begin{array}{l}49,30 \\
48,84 \\
48,65 \\
48,63 \\
50,57\end{array}$ & $\begin{array}{llllllll}1975 & \ldots & \ldots & \ldots & \ldots & \ldots & \ldots & \ldots \\
1976 & \ldots & \ldots & \ldots & \ldots & \ldots & \ldots & \ldots \\
1977 & \ldots & \ldots & \ldots & \ldots & \ldots & \ldots & \ldots \\
1978 & \ldots & \ldots & \ldots & \ldots & \ldots & \ldots & \ldots \\
1979 & \ldots & \ldots & \ldots & \ldots & \ldots & \ldots & \ldots\end{array}$ & $\begin{array}{l}56,30 \\
56,56 \\
57,04 \\
56,68 \\
57,36\end{array}$ \\
\hline $\begin{array}{cccccccc}1970 & \ldots & \ldots & \ldots & \ldots & \ldots & \ldots & \ldots \\
1971 & \ldots & \ldots & \ldots & \ldots & \ldots & \ldots & \ldots \\
1972 & \ldots & \ldots & \ldots & \ldots & \ldots & \ldots & \ldots \\
1973 & \ldots & \ldots & \ldots & \ldots & \ldots & \ldots & \ldots \\
1974 & \ldots & \ldots & \ldots & \ldots & \ldots & \ldots & \ldots\end{array}$ & $\begin{array}{l}52,35 \\
52,57 \\
53,49 \\
54,97 \\
54,98\end{array}$ & $\begin{array}{llllllll}1980 & \ldots & \ldots & \ldots & \ldots & \ldots & \ldots & \ldots \\
1981 & \ldots & \ldots & \ldots & \ldots & \ldots & \ldots & \ldots \\
1982 & \ldots & \ldots & \ldots & \ldots & \ldots & \ldots & \ldots \\
1983 & \ldots & \ldots & \ldots & \ldots & \ldots & \ldots & \ldots \\
1984 & \ldots & \ldots & \ldots & \ldots & \ldots & \ldots & \ldots\end{array}$ & $\begin{array}{l}58,72 \\
59,84 \\
59,93 \\
60,93 \\
60,98\end{array}$ \\
\hline
\end{tabular}

IVUnNT: Encuesta de Poblución Activa, cuartos trimestres.

\section{TABLA 11}

Población juvenil (varones quince-veintinueve años) y proporción de jóvenes como porcentaje del numero de adultos (varones, treinta-sesenta y cuatro).

España, cifras proyectadas: 1980-2010

\begin{tabular}{|c|c|c|c|c|c|}
\hline$A \bar{n} O$ & $\begin{array}{c}\text { Varones } \\
15.29 \\
\text { (miles) }\end{array}$ & $\begin{array}{c}\text { Proporción } \\
\text { jóvenes } \\
(\%)\end{array}$ & Año & $\begin{array}{c}\text { Varones } \\
15.29 \\
\text { (miles) }\end{array}$ & $\begin{array}{c}\text { Proporción } \\
\text { jóvenes } \\
(\%)\end{array}$ \\
\hline 1980 & $4.414,8$ & 60,04 & 1995 & $4.927,9$ & 57,76 \\
\hline 1981 & $4.504,2$ & 60,64 & 1996 & $4.856,9$ & 56,31 \\
\hline 1982 & $4.589,8$ & 61,17 & 1997 & $4.774,9$ & 54,78 \\
\hline 1983 & $4.669,7$ & 61.63 & 1498 & $4.682,3$ & 53,16 \\
\hline 1984 & $4.7+2,3$ & 62,01 & 1999 & $4.588,2$ & 51,56 \\
\hline 1985 & $4.807,3$ & 62,31 & 2000 & $4.499,3$ & 50,02 \\
\hline 1986 & 4.864 .7 & 62,52 & 2001 & $4.413,6$ & 48,50 \\
\hline 1987 & $4.917,3$ & 62,61 & 2002 & $4.330,5$ & 46,96 \\
\hline 1988 & $4.957,1$ & 62,60 & 2003 & $4.250,5$ & 45,51 \\
\hline 1989 & $4.991,6$ & 62,44 & 2004 & $4.174,0$ & 44,11 \\
\hline 1990 & $5.017,6$ & 62,15 & 2005 & $4.103,2$ & 42,81 \\
\hline 1991 & $5.035,0$ & 61,73 & 2006 & $4.036,9$ & 41,64 \\
\hline 1992 & $5.034,3$ & 61,05 & 2007 & $3.981,7$ & 40,70 \\
\hline 1993 & $5.018,5$ & 60,19 & 2008 & $3.936,4$ & 39,92 \\
\hline 1994 & $4.980,1$ & 59,04 & 2009 & $3.908,7$ & 39,41 \\
\hline
\end{tabular}

Fuente: Proyeción de la población española para el periodo 1980-2010, tomo 1, Instituto Nacional de Estadística, Madrid, 1987. 
noventa (sólo en el año 2007 bajará de los cuatro millones). En cambio, la proporción relativa podrá descender antes: el máximo se acaba de atravesar en 1987-1988 ${ }^{13}$, en el año 1994 se bajará del 60 por 100 y en el año 2000 se cruzará la barrera del 50 por 100 . Podrá advertirse la coherencia de estas proyecciones con los datos del tamaño relativo de las cohortes de mujeres, al atravesar la frontera de los veinticinco años (tabla 6 y figura 6 ).

Pues bien, de hacer caso a Easterlin, y puesto que la proporción relativa de jóvenes ya está comenzando a descender en España, esto quiere decir que la caída de la fecundidad habría terminado: tras tocar fondo, en cualquier momento comenzará a ascender ( $s i$ no lo está haciendo ya, vía nupcialidad en alza). Pero si nos curamos en salud, y en vez de fijarnos como Easterlin en la proporción relativa, lo hacemos en el tamaño de las cohortes (como aconseja la sociología de la edad), deberemos esperar hasta 1992, que es cuando se alcanzará la cifra más elevada tanto de mujeres jóvenes (tabla 6: tamaño de las cohortes de mujeres que cumplen veinticinco años) como de jóvenes varones (tabla 11: proyección del número de varones de quince a veintinueve años). Sólo el tiempo podrá decirnos a qué carta quedarnos, si a la de la proporción relativa o a la del tamaño. El tiempo y la comparación internacional.

En las tablas 12 a 15 se contienen los datos de proporción relativa de jóvenes, de nupcialidad y de fecundidad de cuatro países europeos que atraviesan, como nosotros, el punto de inflexión de la fase más baja del ciclo demográfico (exceso de jóvenes, baja nupcialidad y baja fecundidad): son Dinamarca (tabla 12), Holanda (tabla 13), Alemania (tabla 14) e Italia (tabia 15). Pues bien, la evidencia parece dar la razón a Easterlin: no es el tamaño de las cohortes, sino la proporción relativa lo que cuenta.

Dinamarca es quizá el mejor ejemplo ${ }^{14}$. En 1982 se alcanza la máxima proporción relativa, mientras que hasta 1990 no se alcanza el máximo tamaño de cohorte. Pues bien, a partir de 1983 comienza a ascender con puntualidad tanto la nupcialidad como, al año siguiente, la fecundidad. Y lo mismo

${ }^{13}$ En anteriores publicaciones, especialmente en Gil Calvo (1984) y Gil Calvo (1985), adelanté otras estimaciones del calendario español del modelo Easterlin que, por no disponerse todavía de la publicación de los datos correspondientes al Censo de 1981 y a sus proyecciones, se revelaron erradas. Pero la lógica del modelo, como demuestra la recuperación del empleo iniciada en 1985, sí ha respondido a aquellas previsiones.

14 Parece ser, tal y como publican en un artículo periodístico Fernández Cordón y Leguina (1989), que donde más intensamente se ha recuperado la fecundidad ha sido en Suecia. Por desgracia, los datos que publica el Demograpbic Yearbook son más pobres y tardíos que los de Eurostat. Pero, por los pocos datos que he visto publicados, el caso de Suecia parece idéntico al de Dinamarca. La proporción relativa de jóvenes está descendiendo ya, desde un 48 por 100 en 1981 hasta un 47 por 100 en 1985. En consecuencia, tanto la nupcialidad como la natalidad tocaron fondo en 1983, año a partir del cual han comenzado a incrementarse de modo ininterrumpido. Pero, tal y como deberá señalarse después y de acuerdo al modelo diseñado por Anna Cabré en la p. 12 de su trabajo tantas veces citado (Cabré y Pujadas, 1987), sólo está ascendiendo, por el momento, la nupcialidad y la fecundidad de las mujeres mayores de veinticinco años, mientras los índices de las menores de esa edad siguen todavía cayendo a la baja. 


\section{TABLA 12}

Dinamarca: colución reciente de la proporción de jóvenes, la nupcialidad y la lecundidad

\begin{tabular}{|c|c|c|c|c|c|c|c|c|c|c|c|c|}
\hline Año. & $\begin{array}{c}\text { Varones } \\
15-29 \\
\text { (miles) } \\
\text { (1) }\end{array}$ & $\begin{array}{c}\text { Propor. } \\
\text { jóvenes } \\
(\%) \\
(2)\end{array}$ & $\begin{array}{l}\text { Total } \\
\text { matrim. } \\
\text { (miles) } \\
\text { (3) }\end{array}$ & $\begin{array}{l}\text { Eidad } \\
\text { media } \\
\text { novia } \\
(4)\end{array}$ & $\begin{array}{l}\text { Totil } \\
\text { nacim. } \\
\text { (miles) } \\
(5)\end{array}$ & $\begin{array}{c}\text { Tasa } \\
\text { por mil } \\
\text { babit. } \\
\text { (6) }\end{array}$ & $\begin{array}{l}\text { Primer } \\
\text { nacim. } \\
\text { (miles) } \\
\text { (7) }\end{array}$ & $\begin{array}{l}\text { Edad } \\
\text { media } \\
\text { madre } \\
(8)\end{array}$ & $\begin{array}{l}\text { Indice } \\
\text { sintet. } \\
\text { fecund. } \\
\text { (9) }\end{array}$ & $\begin{array}{l}\text { Hijos } \\
\text { por mil } \\
\text { mujerces } \\
20-24 \\
(10)\end{array}$ & $\begin{array}{l}\text { Hijos } \\
\text { por mil } \\
\text { mujerces } \\
25-29 \\
(11)\end{array}$ & $\begin{array}{l}\text { Hijos } \\
\text { por mil } \\
\text { mujeres } \\
30-34 \\
(12)\end{array}$ \\
\hline 1980 & 584 & 53,7 & 19,6 & 24,8 & 57,3 & 11,2 & 26,2 & 24,6 & 1,55 & 102 & 118 & 55 \\
\hline 1981 & 586 & 53,7 & 18,5 & 25,1 & 53,1 & 10,4 & 24,3 & 24,8 & 1,44 & 92 & 111 & 52 \\
\hline 1982 & 592 & 54,0 & 17,7 & 25,4 & 52,7 & 10,3 & 23,9 & 25,0 & 1,43 & 88 & 113 & 55 \\
\hline 1983 & 595 & 53,9 & 19,5 & 25,8 & 50,8 & 9,9 & 23,4 & 25,2 & 1,38 & 80 & 112 & 56 \\
\hline 1984 & 594 & 53,5 & 20,9 & 26,1 & 51,8 & 10,1 & 24,2 & 25,4 & 1,40 & 78 & 113 & 59 \\
\hline 1985 & 594 & 53,1 & 21,5 & 26,3 & 537 & 10,5 & 25,1 & 25,5 & 145 & 77 & 118 & 64 \\
\hline 1986 & 596 & 53,0 & 22,7 & 26,5 & 55,3 & 10,8 & 26,0 & 25,7 & 1,48 & 75 & 120 & 68 \\
\hline 1987 & 600 & 53,0 & 22,7 & 26,8 & 56,2 & 11,8 & 26,4 & 25.9 & 1,50 & 71 & 122 & 71 \\
\hline 1990 & 603 & 52,3 & & & & & & & & & & \\
\hline 1995 & 570 & 47,0 & & & & & & & & & & \\
\hline 2000 & 498 & 39,1 & & & & & & & & & & \\
\hline
\end{tabular}

Notas: (1) Cantidad absoluta de jóvenes, en miles de varones de 15 a 29 años.-(2) Proporción relativa de jóvenes, como porcentaje del número de varones adultos de 30 a 64 años.--(3) Número total de matrimonios (mujeres), en miles.--(4) Edad media de las mujeres al contraer primeras nupcias.-(5) Número total de nacimientos, en miles.-16) Número de nacimientos por mil habitantes.-(7) Número de primeros nacimientos, en miles.-(8) Edad media de las madres en sus primeros alumbramientos.-(9) Suma de nacimientos reducidos, equivalente al número medio de hijos por mujer.-(10), (11) y (12) Tasas específicas de fecundidad por edad de las madres, o número de hijos por cada mil mujeres de cada grupo de edad.

FuENTE: Eurostat. 
TABLA 13

Holanda: evolución reciente de la proporción àe jóvenes, la nupcialidad y la fecundidad

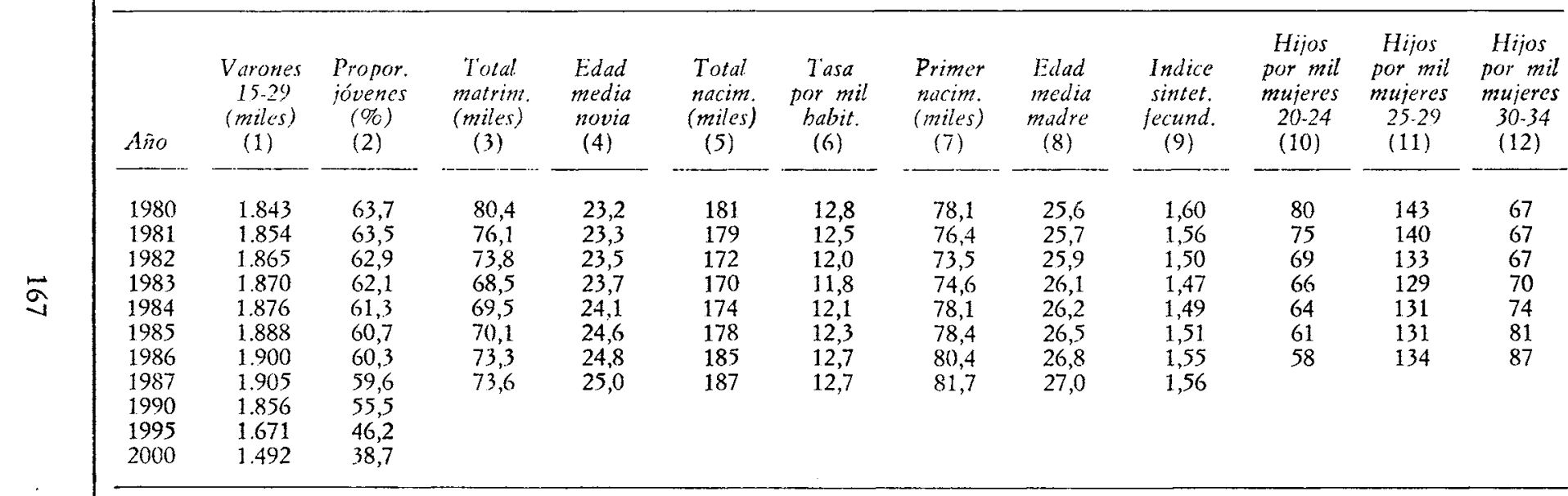

Notas: (1) Cantidad absoluta de jóvenes, en miles de varones de 15 a 29 años.-(2) Proporción relativa de jóvenes, como porcentaje del número de varones adultos de 30 a 64 años.-(3) Número total de matrimonios (mujeres), en miles.-(4) Edad media de las mujeres al contraer primeras nupcias.-(5) Número total de nacimientos, en miles.-(6) Número de nacimientos por mil habitantes.-(7) Número de primeros nacimientos, en miles.-(8) Edad media de las madres en sus primeros alumbramientos.-(9) Suma de nacimientos reducidos, equivalente al número medio de hijos por mujer.-(10), (11) y (12) Tasas específicas de fecundidad por edad de las madres, o número de hijos por cada mil mujeres de cada grupo de edad.

FUENTE: Eurostat. 


\section{TABLA 14}

Alemania (RFA): evolución reciente de la proporción relativa de jóvenes, la nupcialidad y la fecundidad

\begin{tabular}{|c|c|c|c|c|c|c|c|c|c|c|c|c|}
\hline Años & $\begin{array}{c}\text { Varones } \\
15-29 \\
\text { (miles) } \\
(1)\end{array}$ & $\begin{array}{c}\text { Propor. } \\
\text { jóvenes } \\
\text { (\%) } \\
(2)\end{array}$ & $\begin{array}{l}\text { Total } \\
\text { matrim. } \\
\text { (miles) } \\
(3)\end{array}$ & $\begin{array}{c}\text { Edad } \\
\text { media } \\
\text { novia } \\
(4)\end{array}$ & $\begin{array}{l}\text { Total } \\
\text { nacim. } \\
\text { (miles) } \\
(5)\end{array}$ & $\begin{array}{c}\text { Tasa } \\
\text { por mil } \\
\text { babit. } \\
\text { (6) }\end{array}$ & $\begin{array}{c}\text { Primer } \\
\text { nacim. } \\
\text { (miles) } \\
(7)\end{array}$ & $\begin{array}{l}\text { Edad } \\
\text { media } \\
\text { madre } \\
(8)\end{array}$ & $\begin{array}{c}\text { Indice } \\
\text { sintet. } \\
\text { fecund. } \\
\text { (9) }\end{array}$ & $\begin{array}{l}\text { Hijos } \\
\text { por mil } \\
\text { mujeres } \\
20-24 \\
(10)\end{array}$ & $\begin{array}{l}\text { Hijos } \\
\text { por mil } \\
\text { mujeres } \\
25.29 \\
(11)\end{array}$ & $\begin{array}{c}\text { Hijos } \\
\text { por mil } \\
\text { mujeres } \\
30-34 \\
(12)\end{array}$ \\
\hline 1980 & 7.293 & 56,3 & 299 & 23,4 & 621 & 10,1 & 279 & 25,2 & 1,44 & 82 & 107 & 65 \\
\hline 1981 & 7.390 & 56,7 & 294 & 23,6 & 625 & 10,1 & 280 & 25,3 & 1,44 & 79 & 107 & 65 \\
\hline 1982 & 7.537 & 56,9 & 293 & 23,8 & 621 & 10,1 & 280 & 25,5 & 1,41 & 75 & 107 & 64 \\
\hline 1983 & 7.593 & 56,6 & 292 & 24,1 & 594 & 9,7 & 268 & 25,7 & 1,33 & 69 & 103 & 62 \\
\hline 1984 & 7.643 & 56,3 & 294 & 24,4 & 584 & 9,5 & 258 & 26,0 & 1,29 & 62 & 102 & 62 \\
\hline 1985 & 7.669 & 56,2 & 294 & 24,6 & 586 & 9,6 & 257 & 26,2 & 1,28 & 58 & 102 & 64 \\
\hline 1986 & 7.669 & 55,9 & 298 & 24,9 & 626 & 10,3 & 270 & 26,4 & 1,35 & 58 & 107 & 70 \\
\hline 1987 & 7.654 & 55,2 & 307 & 25,2 & 642 & 10,5 & 280 & 26,5 & 1,36 & & & \\
\hline 1990 & 7.097 & 49,2 & & & & & & & & & & \\
\hline 1995 & 5.912 & 38,7 & & & & & & & & & & \\
\hline 2000 & 4.926 & 30,9 & & & & & & & & & & \\
\hline
\end{tabular}

Notas: (1) Cantidad absoluta de jóvenes, en miles de varones de 15 a 29 años.-(2) Proporción relativa de jóvenes, como porcentaje del número de varones adultos de 30 a 64 años.-(3) Número total de matrimonios (mujeres), en miles.-(4) Edad media de las mujeres al contraer primeras nupcias.-(5) Número total de nacimientos, en miles.-(6) Número de nacimientos por mil habitantes.-(7) Número de primeros nacimientos, en miles.-(8) Edad media de las madres en sus primeros alumbramientos.-19) Suma de nacimientos reducidos, equivalente al número medio de hijos por mujer.--(10), (11) y (12) Tasas específicas de fecundidad por edad de las madres, o número de hijos por cada mil mujeres de cada grupo de edad.

FUENTE: Eurostat. 
TABLA 15

Italia: evolución reciente de la proporción de jóvenes, la nupcialidad y la fecundidad

\begin{tabular}{|c|c|c|c|c|c|c|c|c|c|c|c|c|}
\hline$A \tilde{n}(s)$ & $\begin{array}{c}\text { Varones } \\
15.29 \\
\text { (miles) } \\
\text { (1) }\end{array}$ & $\begin{array}{c}\text { Propor. } \\
\text { jóvenes } \\
(\%) \\
(2)\end{array}$ & $\begin{array}{c}\text { Total } \\
\text { matrim. } \\
\text { (miles) } \\
(3)\end{array}$ & $\begin{array}{l}\text { Edad } \\
\text { media } \\
\text { novia } \\
(4)\end{array}$ & $\begin{array}{c}\text { Total } \\
\text { nacim. } \\
\text { (miles) } \\
(5)\end{array}$ & $\begin{array}{c}\text { Tasa } \\
\text { por mil } \\
\text { babit. } \\
(6)\end{array}$ & $\begin{array}{l}\text { Primer } \\
\text { nacim. } \\
\text { (miles) } \\
(7)\end{array}$ & $\begin{array}{l}\text { Edad } \\
\text { media } \\
\text { madre } \\
(8)\end{array}$ & $\begin{array}{l}\text { Indice } \\
\text { sintet. } \\
\text { fecund. } \\
\text { (9) }\end{array}$ & $\begin{array}{l}\text { Hijos } \\
\text { por mil } \\
\text { mujeres } \\
20-24 \\
(10)\end{array}$ & $\begin{array}{c}\text { Hijos } \\
\text { por mil } \\
\text { mujcres } \\
25.29 \\
(11)\end{array}$ & $\begin{array}{l}\text { Hijos } \\
\text { por mil } \\
\text { mujeres } \\
30-34 \\
(12)\end{array}$ \\
\hline 1980 & & & 323 & 24,1 & 640 & 11,3 & 279 & 24,4 & 1,69 & 101 & 114 & 67 \\
\hline 1981 & 6.436 & 54,1 & 317 & 24,0 & 623 & 11,0 & 271 & 24,5 & 1.62 & 95 & 112 & 65 \\
\hline 1982 & 6.529 & 54,3 & 312 & 24,1 & 619 & 10,9 & 271 & 24,4 & 1,59 & 92 & 110 & 66 \\
\hline 1983 & 6.619 & 54,9 & 301 & 24,1 & 602 & 10,6 & 265 & 24.7 & 1,52 & 85 & 106 & 65 \\
\hline 1984 & 6.688 & 55,1 & 298 & 24,3 & 586 & 10,3 & 258 & 24,9 & 1,46 & 79 & 103 & 65 \\
\hline 1985 & 6.798 & 55,3 & 296 & 24,5 & 575 & 10,1 & 254 & 25,1 & 1,41 & 77 & 100 & 62 \\
\hline 1986 & 6.885 & 55,9 & 297 & 24,7 & 555 & 9,7 & & & & & & \\
\hline 1987 & 6.968 & 56,3 & 305 & & 552 & 9,6 & & & & & & \\
\hline 1990 & 7.016 & 56,0 & & & & & & & & & & \\
\hline 1995 & 6.551 & 50,2 & & & & & & & & & & \\
\hline 2000 & 5.691 & 41,9 & & & & & & & & & & \\
\hline
\end{tabular}

Notas: (1) Cantidad absoluta de jóvenes, en miles de varones de 15 a 29 años.-(2) Proporción relativa de jóvenes, como porcentaje del número de varones adultos de 30 a 64 años.-(3) Número total de matrimonios (mujeres), en miles.-(4) Edad media de las mujeres al contraer primeras nupcias.-(5) Número total de nacimientos, en miles.-(6) Número de nacimientos por mil habitantes.-(7) Número de primeros nacimientos, en miles.-(8) Edad media de las madres en sus primeros alumbramicntos.-(9) Suma de nacimientos reducidos, equivalente al número medio de hijos por mujer.-110), (11) y (12) Tasas específicas de fecundidad por edad de las madres, o número de hijos por cada mil mujeres de cada grupo de edad.

FuenTE: Eurostat. 
sucede en Holanda y Alemania, si bien con mayor retraso: no bien comienza a descender la proporción relativa de jóvenes, y aunque todavía no lo hayá empezado a hacer el tamaño de la cohorte de jóvenes, la nupcialidad, y luego la fecundidad, se reactivan.

El caso de Italia es distinto, lo que puede corroborar mejor al modelo Easterlin. En efecto, allí todavía no ha comenzado a descender la proporción relativa de jóvenes (su máximo habrá de producirse entre 1987 y 1990) y mucho menos el tamaño de las cohortes jóvenes (que no alcanzarán su máximo hasta 1990). En consecuencia, la fase baja del ciclo demográfico italiano todavía no ha terminado de tocar fondo, la fecundidad sigue desccndiendo y todavía no se ha logrado atravesar el punto de inflexión (que, con arreglo a la lógica del modelo que venimos comentando, parece por otra parte a punto de producirse, como reve!a quizá el tímido ascenso reciente del número de matrimonios).

$Y$ esto es parecido a lo que sucede con las cifras españolas (tablas 16 y 17), lo que parece indicar una diferencia entre los ciclos demográficos del norte de Europa (Dinamarca, Holanda y Alemania) y del sur mediterráneo (Italia y España). En etecto, como ya pudimos ver con la figura 6, en España se produjo un tardío repunte del baby-boom terminal que generó cohortes extraordinariamente numerosas durante la primera mitad de los años setenta. Esta singularidad parece deberse a que, si bien el baby-boom europeo comenzó a mediados de los cuarenta, en España no apareció hasta mediados los cincuenta, por lo que a comienzos de los setenta, como se advierte en la figura 6 , se produjo una inesperada reducción del tamaño de las cohortes jóvenese (correspondiente a las bajas natalidades de comienzos de los cincuenta), que dio lugar al consecuente repunte al alza de la fecundidad, prolongándose así la duración del baby-boom terminal. Por consiguiente, mientras en el norte de Europa yal se cstá reduciendo la proporción y el tamaño de las cohortcs jóvenes, en España (como quizá en Italia) todavía siguen creciendo, si bien el punto de inflexión se halla muy próximo.

Por ello, aquí no ha podido comenzar todavía la recuperación de la fecundidad. Ahora bien, cabc en lo posible, sin embargo, que ya se esté recuperando la fecundidad de las mujeres mayores de treinta años, pues, en efecto, la nupcialidad de las mujeres con edades de veinticinco a veintinueve y de trcinta a treinta y cuatro años ya se está incrementando de nuevo. $Y$ ello parce indudablemente relacionado con el hecho de que en España la proporción relativa de jóvenes ya está disminuyendo (aunque el tamaño de las cohortes jóvenes no puedal hacerlo hasta 1992), tras haber alcanzado su máximo en 1987.

$\mathrm{Y}$ el mismo argumento puede ser esgrimido para explicar por qué la fecundidad de las mujeres madrileñas mayores de veinticinco y treinta años todavía no se ha recuperado, a pesar de que sí lo haya hecho ya su nupcialidad (tabla 17). En efecto, en la Comunidad Autónoma de Madrid sucede 
TABLA 16

España: evolución reciente de la proporción de jóvenes, la natalidad y la nupcialidad

\begin{tabular}{|c|c|c|c|c|c|c|c|c|c|c|c|c|}
\hline$A \tilde{n} 0$. & $\begin{array}{c}\text { Varones } \\
15-29 \\
\text { (miles) } \\
\text { (1) }\end{array}$ & $\begin{array}{c}\text { Propor. } \\
\text { jóvenes } \\
\text { (\%) } \\
\text { (2) }\end{array}$ & $\begin{array}{c}\text { Total } \\
\text { nacim } \\
\text { (miles) } \\
\text { (3) }\end{array}$ & $\begin{array}{c}\text { Tasa } \\
\text { por mil } \\
\text { babit. } \\
\text { (4) }\end{array}$ & $\begin{array}{c}\text { Total } \\
\text { matrim. } \\
\text { (miles) } \\
(5)\end{array}$ & $\begin{array}{c}\text { Tasa } \\
\text { por mil } \\
\text { babit. } \\
(6)\end{array}$ & $\begin{array}{l}\text { Matrim. } \\
\text { por mil } \\
\text { muieres } \\
15-19 \\
(7)\end{array}$ & $\begin{array}{l}\text { Matrint } \\
\text { por ntil } \\
\text { muiceres } \\
20.24 \\
(8)\end{array}$ & $\begin{array}{c}\text { Matrin. } \\
\text { por mil } \\
\text { muiceres } \\
25.29 \\
19 j\end{array}$ & $\begin{array}{l}\% \text { tolal } \\
\text { matrim. } \\
\text { mujeres } \\
15-19 \\
(10)\end{array}$ & $\begin{array}{l}\% \text { total } \\
\text { matrim. } \\
\text { mujeres } \\
20.24 \\
\text { (11) }\end{array}$ & $\begin{array}{l}\% \text { total } \\
\text { matrim. } \\
\text { muicres } \\
25-29 \\
(12)\end{array}$ \\
\hline 1980 & 4.415 & 60,0 & 571 & 15,2 & 221 & 5,9 & 28 & $8 t$ & 29 & 20,4 & 55,1 & 16,8 \\
\hline 1981 & 4.504 & 60,6 & 533 & 14,1 & 202 & 5,4 & 24 & 76 & 27 & 19,2 & 55,6 & 17,5 \\
\hline 1982 & 4.590 & 61,2 & 516 & 13,6 & 193 & 5,1 & 22 & 68 & 28 & 18,1 & 53,6 & 18,9 \\
\hline 1983 & 4.670 & 61,6 & 485 & 12,7 & 196 & 5,1 & 21 & 67 & 30 & 17,1 & 52,4 & 20,5 \\
\hline 1984 & 4.742 & 62,0 & 473 & 12,3 & 198 & 5,2 & 20 & 64 & 32 & 16,1 & 51,2 & 22,4 \\
\hline 1985 & 4.807 & 62,3 & 451 & 11,7 & 193 & 5,0 & & & & & & \\
\hline 1986 & 4.865 & 62,5 & 435 & 11,2 & 203 & 5,3 & & & & & & \\
\hline 1987 & 4.914 & 62,6 & & & & & & & & & & \\
\hline 1991 & 5.035 & 61,7 & & & & & & & & & & \\
\hline 1995 & 4.928 & 57,8 & & & & & & & & & & \\
\hline 2000 & 4.499 & 50,0 & & & & & & & & & & \\
\hline
\end{tabular}

Notas: (1) Cantidad absoluta de jóvencs, en miles de varones de 15 a 29 años.--(2) Proporción relativa de jóvenes como porcentaje del número de varones adultos de 30 a 64 años.-(3) Número total de nacimientos, en miles.-(4) Número de nacimientos por: mil habitantes. - (5) Número total de matrimonios, en miles.-(6) Número de matrimonios por mil habitantes.-17), (8) y (9) Tasas específicas de nupcialidad por edad, o número de matrimonios por cada mil mujeres de cada grupo de cdad.--(10), (11) y (12) Cuotas de nupcialidad por edad, o proporción $(\%)$ de mujeres que se casan en cada grupo de edad respecto al total de matrimonios.

Fuente: Instituto Nacional de Fstadística. 
TABLA 17

Comunidad de Madrid: evolución reciente de la proporión relativa de jóvenes, la nupcialidad y la fecundidad

\begin{tabular}{|c|c|c|c|c|c|c|c|c|c|c|c|c|}
\hline$A \tilde{n} o$ & $\begin{array}{c}\text { Varones } \\
15-29 \\
\text { (miles) } \\
\text { (1) }\end{array}$ & $\begin{array}{c}\text { Propor. } \\
\text { jóvenes } \\
\text { (\%) } \\
\text { (2) }\end{array}$ & $\begin{array}{l}\text { Total } \\
\text { matrim. } \\
\text { (miles) } \\
\text { (3) }\end{array}$ & $\begin{array}{c}\text { Matrim. } \\
\text { por mil } \\
\text { mujeres } \\
15-19 \\
\text { (4) }\end{array}$ & $\begin{array}{c}\text { Matrim. } \\
\text { por mil } \\
\text { mujeres } \\
20.24 \\
\text { (5) }\end{array}$ & $\begin{array}{c}\text { Matrim. } \\
\text { por mil } \\
\text { mujeres } \\
25-29 \\
(6)\end{array}$ & $\begin{array}{c}\text { Matrim, } \\
\text { por mil } \\
\text { mujeres } \\
30.34 \\
(7)\end{array}$ & $\begin{array}{c}\text { Total } \\
\text { nacim. } \\
\text { (miles) } \\
(8)\end{array}$ & $\begin{array}{l}\text { Primer } \\
\text { nacim. } \\
\text { (miles) } \\
(9)\end{array}$ & $\begin{array}{c}\text { Hijos } \\
\text { por mil } \\
\text { mujeres } \\
20-24 \\
(10)\end{array}$ & $\begin{array}{c}\text { Hijos } \\
\text { por mil } \\
\text { muicres } \\
25-29 \\
\text { (11) }\end{array}$ & $\begin{array}{c}\text { Hijos } \\
\text { por mil } \\
\text { mujires } \\
30-34 \\
\text { (12) }\end{array}$ \\
\hline 1980 & 545 & 60,2 & 28,8 & 19,6 & 85,4 & 34,9 & 8,7 & 72,8 & 32,2 & 101 & 146 & 91 \\
\hline 1981 & 556 & 60,5 & 25,4 & 15,7 & 74,7 & 31,6 & 7,6 & 68,9 & 30.0 & 91 & 138 & 88 \\
\hline 1982 & 566 & 60,8 & 26,5 & 15,3 & 71,5 & 35,8 & 9,0 & 65,5 & 28.5 & 82 & 133 & 86 \\
\hline 1983 & 576 & 61,0 & 26,7 & 13,7 & 68,6 & 38,5 & 9,6 & 60,7 & 26,8 & 72 & 125 & 79 \\
\hline 1984 & 584 & 61,2 & 26,0 & 12,2 & 63,3 & 40,7 & 10,2 & 59,5 & 26,8 & 66 & 121 & 81 \\
\hline 1985 & 592 & 61,2 & 22,8 & & & & & 57,7 & & & & \\
\hline 1986 & 603 & 61,6 & 24,6 & 9,7 & 54,5 & 42,7 & 10,5 & 55,3 & & 51 & 110 & 76 \\
\hline 1987 & 612 & 61,9 & 24,3 & 9,1 & 51,6 & 44,1 & 10,6 & 53,3 & & 46 & 107 & 74 \\
\hline 1988 & 621 & 62,2 & & & & & & & & & & \\
\hline 1989 & 629 & 62,3 & & & & & & & & & & \\
\hline 1990 & 636 & 62,2 & & & & & & & & & & \\
\hline
\end{tabular}

Notas: (1) Cantidad absoluta de jóvenes, en miles de varones de 15 a 29 años.-(2) Proporción relativa de jóvenes como porcentaje del número de varones adultos de 30 a 64 años.-(3) Número total de matrimonios, en miles.-(4), (5), (6) y (7) Tasas específicas de nupcialidad femenina por edad, o número de matrimonios por cada mil mujeres en cada grupo de edad.-(8) Número total de nacimientos, en miles.-(9) Número total de primeros nacimientos, en miles.-(10), (11) y (12) Tasas específicas de fecundidad por edad, o número de hijos por cada mil mujeres de cada grupo de edad.

FuenTes: Instituto Nacional de Estadística y Anuario Estadístico de la Comunidad de Madrid. 
que los últimos coletazos de su baby-boom terminal fueron mucho más intensos, y bastante más tardíos o prolongados en el tiempo, que sus equivalentes en el conjunto global español ${ }^{15}$. En consecuencia, la proporción relativa de jóvenes sigue todavía creciendo en Madrid cuando ya desciende en el resto de España, por lo que no tocará fondo hasta 1989, cuando alcance su máximo por fin.

En suma, la evidencia europea, registrada en los datos de las tablas 12 a 17, parece confirmar las predicciones del modelo Easterlin: tanto en positivo (cuando la proporción relativa de jóvenes comienza a descender se recupera primero la nupcialidad y luego la fecundidad) como en negativo también (aunque el ciclo económico ya se esté recuperando, la nupcialidad y la fecundidad siguen estancadas hasta tanto no comience a descender la proporción relativa de jóvenes: según parece revelarse en el caso italiano y en el español, especialmente en Madrid).

Pero por otra parte, hay algo en el modelo Easterlin que la evidencia europea desmiente. En efecto, se diría que siendo la escasez de jóvenes el factor recuperador desencadenante, y puesto que quienes comienzan a escasear son los más jóvenes (los de quince a diecinueve años primero, los de veinte a veinticuatro luego y los de veinticinco a veintinueve después), la recuperación de la nupcialidad y la fecundidad debiera comenzar, también, por los más jóvenes: adelantándose las bodas y los hijos de los menores de veinticinco años y comenzando a descender la edad media en que se contraen primeras nupcias o se producen los primeros nacimientos. Pues bien, no es así. Por el contrario, tal y como han observado Cabré y Pujadas para el caso catalán ${ }^{16}$, el inicio de las nuevas fases ascendentes, tras superarse el punto de inflexión en que el ciclo toca fondo, es protagonizado por las cohortes de mujeres mayores de veinticinco años que se habian visto obligadas a posponer su calendario reproductor (y que ahora aprovechan para completarlo antes de que sea demasiado tarde), y no por las más escasas y reducidas cohortes de mujeres más jóvenes. Al menos, así parecen confirmarlo también los datos de las tablas 12 a 17.

15 En otra parte acabo de analizar las singularidades del ciclo demográfico de la Comunidid de Madrid. Véase, al respecto, Gil Calvo (1989).

in Véase Cabré y Pujadas (1987), ob. cit., p. 12. 


\section{BIBLIOGRAFIA}

Becker, Gary (1981): Tratado sobre la familia, Alianza, Madrid.

Binstock, Robert, y Shanas, Ethel (1985): Handbook of Aging and the Sucial Science, Van Nostrand Reinholt, Nueva York.

Cabré, Anna, y Pujadas, Isabe! (1987): «La fecundidad en Cataluña desde 1922» (mimeografiado), ponencia presentada al Primer Congreso Hispano-Luso-Italiano de Demografía Histórica, Barcelona, abril.

De Miguel, Carmen, y Agüero, Isabel (1986): «Evolución demográfica y oferta de fuerza de trabajo», en Álberto Olano (coord.), Tendencias demográficas y planificación éconómica, Mineco, Madrid.

Easterlin, Richard (1968): Population, Labor Force, and Long Swings in Economic Growth, National Bureau of Economic Research, Nueva York.

- (1987): Birth and Forlune. The Impact of Numbers on Personal Wellare, 2." ed., Uni. versity of Chicago Press, Chicago.

Easterlin, Richard; Watcher, Michael, y Watcher, Susan (1978): «Demographic Influences on Economic Stability: The United States Experience», Population and Development Review, marzo, pp. 1 a 22.

Featherman, David, y Lerner, Richard (1985): "Ontogenesis and Sociogenesis», American Sociolugical Review, vol. 50, núm. 5, octubre, pp. 659 a 676.

Fernández, Juan (coord.) (1988): Nuevas perspectivas en el desarrollo del sexo y el género, Pirámide, Madrid.

Fernández Cordón, Juan Antonio (1986): "Análisis longitudinal de la fecundidad en España», en Alberto Olano (coord.), Tendencias demográficas y planificución cconómica, Mineco, Madrid.

Fernández Cordón, Juan Antonio, y Leguina, Joaquín (1989): « ¿ De qué hablamos cuan. do hablamos de demografía?", diario El Pais, 17 mayo, p. 14.

Fernández Méndez Andes, Fernando (1985): La participación laboral de la mujer, Ministerio de Trabajo, Madrid.

- (1989): "Actividad, salarios y ocupación de la mujer en España», en Fernández, Muro y ToHaria, El mercado de trabajo cn España, Fundación IESA, Madrid.

Garrido Menina, Luis (1988): «Para el estudio del mercado de trabajo. Integración laboral en España (EPA 66/86-ECVTE 85)», tesis doctoral (mimeografiada), Universidad Complutense de Madrid.

Giele, Janet (1988): «Gender and Sex Roles», en Neil Smelser, Handbook of Sociology, Chicago, pp. 291 a 323.

Gil Calvo, Enrique (1984): «La tendencia futura del paro y la fecundidad», REIS, núm. 27, julio-septicmbre.

- (1985): Los depredadores audiovisuales. Juventud urbana y cultura de masas, Tecnos, Madrid.

- (1986 a): «Demografía y dependencia en la juventud. Informe y comentario», en Luis Garrido Medina (coord.), Reparto de trabajo y crisis social, Fundación Pablo Iglesias, Madrid.

- (1986 b): «La cstructura de edades y el ocio de los jóvenes: cifras españolas», REIS, núm. 35, julio-septiembre.

- (1989): «El ciclo demográfico en la Comunidad de Madrid», Economia y Sociedad, núm. 2, julio:

Hewletr, Svlvia (1987): A Lesser Life: The Mitb of Women's Liberalion in America, William Morrow, Nueva York.

Hirschman, Albert (1982): Interés privado y acción pública, Fondo de Cultura Económica, México.

Kertzer, David, y Keitur, Jennic (1984): Age and Antbropological Tbeory, Cornell University Press, Ithaca, Nueva York.

Riley, Mathilda (1979): Aging from Birlh to Deatb. Vol. 1: Interdisciplinary Perspectives, Westview Press, Boulder, Colorado.

Riley, Mathilda; Johnson, Marilyn, y Foner, Anne (1972): Aging and Society. Vol. III. A Sociology of Age Stratification, Russell Sage Foundation, Nueva York.

Riley, Mathilda; Abeles, Ronald, y Teitelbaum, Michael (1981): Aging from Birth to Death. Vol. 2: Sociotemporal Perspectives, Westview Press, Boulder, Colorado. 
Riley, Mathilda; Foner, Anne, y Waring, Joan (1988): «Sociology of Age», en Neil Smelser, Handbook of Sociology, University of Chicago Press, Chicago, pp. 243 a 290. Ryder, Norman (1965): "The cohort as a Concept in the Study of Social Change», American Sociological Review, vol. 30 , pp. 843 a 861 .

- (1968): "Análisis de cohortes», en Enciclopedia Internacional de Ciencias Sociales, vol. 2, Aguilar, Madrid, pp. 434 a 438 .

SCHLEsinger, Arthur (1986): Los ciclos de la bistoria americana, Alianza, Madrid.

Smelser, Neil (1988): Handbook of Sociology, University of Chicago Press, Chicago.

WeEks, John (1981): Sociología de la población, Alianza, Madrid.

Zárraga, José Luis (1985): La inserción de los jóvenes en la sociedad, Ministerio de Cul. tura, Madrid. 